\title{
Cellular and Synaptic Modulation Underlying Substance P-Mediated Plasticity of the Lamprey Locomotor Network
}

\author{
David Parker and Sten Grillner \\ Nobel Institute for Neurophysiology, Department of Neuroscience, Karolinska Institute, S-17177, Stockholm, Sweden
}

The tachykinin substance $\mathrm{P}$ modulates the lamprey locomotor network by increasing the frequency of NMDA-evoked ventral root bursts and by making the burst activity more regular. These effects can last in excess of $24 \mathrm{hr}$. In this paper, the effects of substance $P$ on the synaptic and cellular properties of motor neurons and identified network interneurons have been examined.

Substance $P$ potentiated the amplitude of monosynaptic glutamatergic inputs from excitatory interneurons and reticulospinal axons. The amplitude and frequency of miniature EPSPs was increased, suggesting that the synaptic modulation was mediated presynaptically and postsynaptically. The postsynaptic modulation was caused by a specific effect of substance $P$ on the NMDA component of the synaptic input, whereas the presynaptic component was calciumindependent. Substance P did not affect monosynaptic glycinergic inputs from lateral interneurons, crossed inhibitory interneurons, or ipsilateral segmental interneurons or postsynaptic

To provide a mechanistic explanation of behavioral or network modulation, the circuitry underlying the network or behavioral response needs to be known and the effects of neuromodulators studied on relevant identified cells and synaptic connections (Harris-Warrick et al., 1992; Byrne and Kandel, 1996). Because of the complexity of the vertebrate nervous system, this type of analysis is often difficult to perform, particularly in mammals. It has been possible, however, to account for the cellular basis of locomotor activity in lower vertebrate preparations (Xenopus embryo, Roberts, 1990; lamprey, Grillner et al., 1995). The ability to activate locomotor networks in the isolated lamprey spinal cord, together with the cellular and synaptic information available, allows network modulation to be examined at the level of identified neurons and monosynaptic connections. In this paper, the cellular and synaptic mechanisms responsible for a longlasting ( $>24 \mathrm{hr}$ ) tachykinin-induced modulation of the locomotor network are investigated (Parker et al., 1998).

Tachykinins are present in the lamprey CNS (Van Dongen et al., 1986; Waugh et al., 1995). Tachykinin immunoreactivity is found in the dorsal root, dorsal column, and dorsal horn, and also

Received May 7, 1998; revised July 20, 1998; accepted July 23, 1998.

This work was supported by grants from the Wellcome Trust, Karolinska Institutes Fonder, the Swedish Brain Foundation, the Swedish Medical Research Council (9804, 3026), and the Wallenberg Foundation. Ansgar Büshges, Patriq Fagerstedt, Abdel El Manira, Erik Svensson, and Jesper Tegnér provided constructive criticism of the paper.

Correspondence should be addressed to D. Parker, Nobel Institute for Neurophysiology, Department of Neuroscience, Karolinska Institute, S 17177, Stockholm, Sweden.

Copyright (C) 1998 Society for Neuroscience $\quad 0270-6474 / 98 / 188095-16 \$ 05.00 / 0$
$\mathrm{GABA}_{A}$ or $\mathrm{GABA}_{\mathrm{B}}$ responses, suggesting that it has little effect on inhibitory synaptic transmission.

At the cellular level, substance $P$ increased synaptic inputs, resulting in membrane potential oscillations in motor neurons, crossed caudal interneurons, lateral interneurons, and excitatory interneurons. The spiking in response to depolarizing current pulses was increased in motor neurons, lateral interneurons, and excitatory interneurons, but usually was reduced in crossed inhibitory interneurons. Substance $P$ reduced the calcium-dependent afterhyperpolarization after an action potential in motor neurons and lateral interneurons, but did not affect this conductance in excitatory or crossed inhibitory interneurons.

The relevance of these cellular and synaptic changes to the modulation of the locomotor network is discussed.

Key words: substance P; neuropeptide; neuromodulation; lamprey; synaptic transmission; synaptic plasticity

in a ventromedial spinal cord plexus in which the medial dendrites of motor neurons and network interneurons are located (Van Dongen et al., 1985, 1986). This plexus also contains 5-HT and dopamine (Schotland et al., 1995). In the lamprey, as in higher vertebrates, tachykinins potentiate sensory inputs (Parker and Grillner, 1996). Substance P depolarizes mechanosensory afferents, increases the excitability of mechanosensory afferents and spinobulbar neurons, and presynaptically potentiates excitatory, but reduces inhibitory, synaptic inputs (Parker and Grillner, 1996). At least some of these effects are mediated through a pertussis toxin-insensitive G-protein and protein kinase $\mathrm{C}$ (Parker et al., 1997). This cellular and synaptic modulation is associated at the behavioral level with the potentiation of reflex responses evoked by skin stimulation (M. Ullström, D. Parker, E. Svensson, and S. Grillner, unpublished observations).

In addition to their effects at the sensory level, tachykinins also directly modulate the locomotor network. The frequency of NMDA-evoked locomotor bursts is increased by tachykinins, and the burst activity is made more regular (Parker et al., 1998). The magnitude and time course of this modulation is concentrationdependent. With nanomolar concentrations, the effects last between 1 and $5 \mathrm{hr}$, whereas with $1 \mu \mathrm{M}$, the tachykinin-induced modulation remains unchanged, even after washing for $24 \mathrm{hr}$ (Parker et al., 1998). This long-term network modulation has at least two phases, an initial phase $(\sim 2 \mathrm{hr})$ that is dependent on the protein kinase $\mathrm{C}$-mediated potentiation of cellular responses to NMDA and a prolonged phase ( $>2 \mathrm{hr}$ ) that is dependent on protein synthesis. In this paper, synaptic and cellular effects of tachykinins that may contribute to the network modulation have 
been examined by making single and paired intracellular recordings from motor neurons and identified network interneurons. The tachykinins substance $\mathrm{P}$, neurokinin A, eledoisin, and physalaemin were previously examined at the network level. Because their effects were identical, only the effects of substance $\mathrm{P}$ are examined in this paper.

\section{MATERIALS AND METHODS}

Two species of lamprey (Lampetra fluviatilis and Petromyzon marinus) were used in this study. The network effects of substance $\mathrm{P}$ in these two species have previously been shown to be identical (Parker et al., 1998). Adult male and female lampreys were anesthetized with tricaine methane sulfonate (MS-222; Sandoz, Basel, Switzerland), and the spinal cord and notochord were removed. The spinal cord was isolated, and the connective tissue and meninx primitiva were removed from the dorsal and ventral surfaces. It was then placed ventral side up in a Sylgard-lined (Sikema, Stockholm) chamber. A plastic net was placed over the spinal cord and pinned into the Sylgard to keep the cord stable. Unless stated otherwise, the spinal cord was superfused with Ringer's solution containing, in mM: $138 \mathrm{NaCl}, 2.1 \mathrm{KCl}, 1.8 \mathrm{CaCl} 2,1.2 \mathrm{MgCl} 2,4$ glucose, 2 HEPES, and 0.5 L-glutamine, which was bubbled with $\mathrm{O}_{2}$ and the $\mathrm{pH}$-adjusted to 7.4. The experimental chamber was kept at a temperature of $8-12^{\circ} \mathrm{C}$.

Single or paired intracellular recordings were made from the somata of identified spinal cord neurons using thin-walled glass microelectrodes filled with $4 \mathrm{M} \mathrm{K}$ acetate and with resistances of $\sim 40 \mathrm{M} \Omega$. Somatic recordings were distinguished from axonal recordings by the presence of a slow calcium-dependent afterhyperpolarization $\left(\mathrm{AHP}_{\mathrm{Ca}}\right)$ after the action potential, the level of spontaneous synaptic inputs, and the characteristic slower time constant of the voltage response after a hyperpolarizing current pulse of $-1-3 \mathrm{nA}$. Previously established criteria were used to identify neurons physiologically (Buchanan, 1993). Motor neurons were identified by recording 1:1 orthodromic spikes in the ventral root after current injection into their somata. Inhibitory lateral interneurons (LINs) were identified by their characteristic shapes and positions in the spinal cord (Rovainen, 1974) and by extracellular recordings of 1:1 orthodromic spikes on the ipsilateral caudal region of the spinal cord at least 10 segments from the impaled neuron. Crossed caudal interneurons (CCINs) were identified by recording 1:1 orthodromic spikes on the contralateral caudal spinal cord, again at least 10 segments from the impaled neuron. Excitatory interneurons (EINs) were identified by their ability to elicit monosynaptic excitatory postsynaptic potentials in postsynaptic neurons situated one to three segments ipsilateral and caudal to the EIN. Small inhibitory ipsilateral segmental interneurons (SiINs; Buchanan and Grillner, 1988) were identified by their ability to elicit monosynaptic IPSPs in ipsilateral gray matter neurons, again within one to three segments of the presynaptic cell. The SiINs have small cell bodies, and can thus be readily distinguished from the LINs (Rovainen, 1974). Reticulospinal axons were identified by recording antidromic and orthodromic extracellular spikes on the caudal and rostral ends of the spinal cord. The reticulospinal axons included here had a conduction velocity of at least $2 \mathrm{~m} / \mathrm{sec}$. Monosynaptic potentials were identified by their short, constant latency after presynaptic stimulation at frequencies of $10-20 \mathrm{~Hz}$.

Substance $\mathrm{P}$ was applied to the bath using a peristaltic pump. One micromolar concentration was used in all experiments, because this concentration has been shown to result in the long-lasting modulation of the locomotor network that was the primary focus of this study (Parker et al., 1998). Substance P was applied for $10 \mathrm{~min}$, unless stated otherwise, it taking 4-5 min for the solution in the bath to be replaced. Unless stated otherwise, recordings were made after substance $\mathrm{P}$ had been applied for $10 \mathrm{~min}$.

An Axoclamp 2A amplifier was used for amplification and in discontinuous current-clamp mode for current injection. In all experiments, the membrane potential was kept at the control level (between -60 and -70 $\mathrm{mV}$ ) by injecting depolarizing or hyperpolarizing current through the recording electrode using single electrode current clamp. Switching rates of at least $3 \mathrm{kHz}$ were routinely obtained. The output of the sample and hold amplifier was continuously monitored to ensure complete voltage settling. Axon Instruments (Foster City, CA) software (Axotape and pClamp) was used for writing and triggering stimulation protocols and for data acquisition and analysis using a 486 PC computer equipped with an analog-to-digital interface (Digidata 1200, Axon Instruments).

Action potentials were elicited by $1 \mathrm{msec}$ depolarizing current pulses of 5-20 nA. Four action potentials were elicited at a frequency of $1 \mathrm{~Hz}$ in control, in the presence of substance $\mathrm{P}$, and after wash-off. This stimulation frequency did not result in any activity-dependent changes in the action potential. The action potentials in each trial were averaged for analysis. The amplitude of the action potential was measured as the peak of the spike above the baseline preceding current injection, the early afterhyperpolarization (AHP) by the peak hyperpolarizing potential immediately after the spike, the calcium-dependent AHP $\left(\mathrm{AHP}_{\mathrm{Ca}}\right)$ by the peak hyperpolarization after the early AHP had recovered, and the spike duration at half-height. Spiking and input resistance were examined by injecting $100 \mathrm{msec}$ depolarizing and hyperpolarizing current pulses of 0.5-5 nA into the somata of identified spinal neurons. This was done in the presence of AP5 $(100 \mu \mathrm{M})$, CNQX $(10 \mu \mathrm{M})$, and strychnine $(5 \mu \mathrm{M})$ to block synaptic inputs.

Synaptic transmission was examined by making paired recordings from identified neurons. Synaptic potentials were elicited at a rate of one every $10-30 \mathrm{sec}$. This did not result in any frequency-dependent changes of the synaptic input. Inhibitory glycinergic synaptic transmission was usually $(n=7$ of 11) examined in high divalent cation Ringer's solution (containing in mM: $119.8 \mathrm{NaCl}, 2.1 \mathrm{KCl}, 10.8 \mathrm{CaCl}_{2}, 7.2 \mathrm{MgCl}_{2}, 4$ glucose, 2 $\mathrm{HEPES}$, and $0.5 \mathrm{~L}$-glutamine) to reduce spontaneous synaptic inputs and thus facilitate the examination of the monosynaptic input. Glutamatergic synaptic transmission was usually examined in normal Ringer's solution, because high divalent cation Ringer's solution could reduce or block the NMDA component of the synaptic potential (D. Parker, unpublished observation), an effect that occluded part of the substance P-mediated synaptic modulation (see below). This meant that for the first 10-20 min after substance $\mathrm{P}$ application, there was an increase in spontaneous synaptic inputs and membrane potential oscillations (see Fig. 7). In this case, strychnine $(5 \mu \mathrm{M})$ was used to block spontaneous IPSPs, and the membrane potential was monitored continuously to keep it at the control level.

GABAergic inputs were examined by pressure application of GABA and GABA agonists onto the surface of the spinal cord above the neuron being recorded from. Pulse durations of 50-200 msec were used. Experiments were performed in TTX $(1.5 \mu \mathrm{M})$ to block indirect effects caused by possible actions of GABA on nearby neurons.

Split-bath preparations were used in some experiments. A Vaseline barrier was built to separate the spinal cord into two pools. Fast green was added to one of the pools at the end of the experiment to confirm that the solutions in the two pools did not mix. The results from experiments in which this happened $(n=1)$ were not included in the analysis. Drugs were added to the rostral or caudal pool, depending on the type of experiment performed. The caudal pool was continuously perfused using a peristaltic pump, whereas solutions in the rostral pool were changed regularly (every $10 \mathrm{~min}$ ) using a Pasteur pipette. Intracellular recordings were made from neurons in the caudal pool, within five segments of the Vaseline barrier.

Miniature synaptic potentials were examined in the presence of $1.5 \mu \mathrm{M}$ TTX and in either strychnine $(5 \mu \mathrm{M})$, when examining miniature excitatory postsynaptic potentials, or in kynurenic acid (1 mM), or CNQX (10 $\mu \mathrm{M})$ and AP5 $(100 \mu \mathrm{M})$, when examining miniature inhibitory postsynaptic potentials. Miniature synaptic potentials were digitized at $10 \mathrm{kHz}$. Miniature PSP amplitudes were examined on-line using the peak detect facility of pCLAMP6 (Axon Instruments). This allowed the effects of substance $\mathrm{P}$ on the mEPSP amplitude to be evaluated during the experiment. The amplitude was also measured off-line using FETCHAN (Axon instruments). Off-line analysis of the frequency of the miniature potentials, measured by determining the interval between successive events, was performed using DATAPAC III (Run Technologies). Miniature synaptic potentials were detected by their ability to exceed a preset threshold. All detected events were examined to ensure that they had the rapid rise and slow decay time characteristic of mEPSPs. Substance P did not affect the distribution of noise levels when control experiments were performed in the presence of TTX and $1 \mathrm{~mm}$ kynurenic acid and $5 \mu \mathrm{M}$ strychnine to block glutamatergic and glycinergic inputs (data not shown).

Unless stated otherwise, statistical significance was examined using two-tailed, paired $t$ tests. One-way ANOVA was used for comparisons between multiple groups. A Tukey test was used for post hoc analysis of differences between groups. Statistical significance is given in the text for the effects after $10 \mathrm{~min}$ application of substance $\mathrm{P}$ and after washing for 1-2 hr, because possible long-term effects of substance P were of interest (Parker et al., 1998). Values in the presence of substance P or after washing were compared with control. For the analysis of miniature 
synaptic potentials, a Kolmogorov-Smirnov test was performed on cumulative probability plots of amplitude and frequency histograms. A significant difference between groups was accepted when the Kolmogorov-Smirnov quotient $\left[\mathrm{Q}_{\mathrm{KS}}(\lambda)\right]$ was $<0.01$. Results are expressed as mean \pm SEM; the numbers $(n)$ given in the text refer to the number of cells studied. Only one experiment was performed in each piece of spinal cord, with no more than two pieces of cord being taken from the same animal.

\section{RESULTS}

\section{Effects of substance $P$ on synaptic transmission}

\section{Excitatory synaptic transmission}

The frequency of locomotor bursts can be increased experimentally (Brodin et al., 1985) and in computer simulations (Grillner et al., 1988; Tråven et al., 1993) by increasing the excitatory drive to the network. Computer simulations also suggest that the strength of excitatory inputs may have a role in controlling the burst regularity (Hellgren et al., 1992). The effect of substance P on excitatory synaptic transmission was initially examined by making paired recordings from identified network neurons.

Glutamatergic EINs largely mediate excitatory synaptic transmission in the spinal cord at the segmental level (Buchanan and Grillner, 1987). Paired recordings were made from EINs and ipsilateral motor neurons $(n=2$; Fig. $1 A)$ or unidentified gray matter neurons $(n=4)$. Stable recordings from EINs were difficult to obtain, presumably because of the small size of their somata (Buchanan et al., 1989; Buchanan 1993). However, when stable recordings were possible, the EPSP amplitude was always potentiated by substance $\mathrm{P}$ (Fig. $1 A ; n=6 ; p<0.05$ ). It was, as a rule, not possible to keep the cells long enough to get full recovery of this effect, but in the longest stable recording the EPSP amplitude had largely recovered to control after washing for $40 \mathrm{~min}$ (Fig. $1 A ; p>0.05$ ), suggesting against a long-lasting effect of substance $\mathrm{P}$ on EIN-mediated synaptic transmission. Paired recordings were also made from glutamatergic reticulospinal axons and postsynaptic target neurons. Substance P potentiated reticulospinal inputs in motor neurons $(n=3$ of $5 ; p<0.05)$ and unidentified gray matter neurons $(n=5$ of $5 ; p<0.05)$; in the longest case, the effect recovered after washing for $2 \mathrm{hr}$ (Fig. $1 B$; $p>0.1)$. The early electrical component of the synaptic input was not affected by substance P (Fig. $1 B$ ), suggesting that the potentiation of the EPSP amplitude was not caused by a nonspecific effect on the input resistance or membrane potential of the postsynaptic neuron. Substance $\mathrm{P}$ did not affect the spike amplitude or duration, or the amplitude of the fast calciumindependent AHP of the presynaptic reticulospinal action potential ( $p>0.1 ; n=10$; data not shown).

Substance $\mathrm{P}$ also potentiated the amplitude of excitatory locomotor-related depolarizations (Fig. 1C) evoked in split-bath preparations (see Materials and Methods). In these experiments, NMDA $(50 \mu \mathrm{M})$ was added to the rostral pool to evoke locomotor-related depolarizing inputs in neurons in the caudal pool caused by the activation of descending excitatory neurons (Fig. 1Cii, inset). Strychnine $(5 \mu \mathrm{M})$ was added to the caudal pool to block inhibitory inputs (Safronov et al., 1989). Substance P increased the amplitude of these locomotor-related depolarizations in motor neurons $(n=3)$ and unidentified gray matter neurons $(n=2)$. In addition to locomotor-related depolarizations, substance $\mathrm{P}$ also potentiated the amplitude of spontaneous EPSPs recorded in the absence of TTX (motor neurons, $n=2$ of 3 ; CCINs, $n=2$ of 2; LINs, $n=2$ of 3; Fig. $1 D$ ). Strychnine was again used to block inhibitory inputs. The effects on locomotorrelated depolarizations and spontaneous EPSPs also recovered after washing between 1 and $2 \mathrm{hr}(p>0.1)$. None of the effects on synaptic inputs were associated with a measurable change in the input resistance of the cells studied (see also Fig. 9).

These results suggest that substance $\mathrm{P}$ potentiates glutamatergic synaptic transmission. This synaptic modulation was investigated further by examining the effect of substance $\mathrm{P}$ on spontaneous miniature EPSPs (mEPSPs) recorded in the presence of TTX $(1.5 \mu \mathrm{M})$ and strychnine $(5 \mu \mathrm{M})$ to block spike-evoked release and glycinergic inputs, respectively. These mEPSPs were glutamatergic, because they were blocked by $1 \mathrm{~mm}$ kynurenic acid $(n=3$; data not shown). In control, the mean amplitude of the mEPSPs in all cells was $0.51 \pm 0.27 \mathrm{mV}$. Substance P usually increased the amplitude of mEPSPs in motor neurons ( $n=2$ of 3 ; Fig. $2 A, B)$, CCINs ( $n=1$ of 1 ), and unidentified gray matter neurons $\left(n=2\right.$ of 4 ; mean amplitude, $0.78 \pm 0.37 \mathrm{mV} ; \mathrm{Q}_{\mathrm{KS}}(\lambda)<$ $0.01, n=5)$. In addition to increasing the mEPSP amplitude, substance $\mathrm{P}$ also increased the mEPSP frequency. In contrast to the effect on the mEPSP amplitude, the increased mEPSP frequency occurred in every cell examined (Fig. $2 A, C ; n=8$ of 8 ; $\left.\mathrm{Q}_{\mathrm{KS}}(\lambda)<0.01\right)$. The mEPSP amplitude and frequency recovered to control after washing for between 1 and $2 \mathrm{hr}$. This increase in mEPSP frequency and amplitude suggests that excitatory synaptic transmission is potentiated through presynaptic and postsynaptic mechanisms, respectively (Katz, 1966).

Synaptic inputs can be solely AMPA-kainate-mediated, NMDA- and nonNMDA-mediated, or solely NMDA-mediated (lamprey, Dale and Grillner 1986; rat hippocampus, Bekkers and Stevens, 1989; Xenopus, Sillar and Roberts 1991). Substance P potentiates the amplitude of responses to pressure-applied NMDA in lamprey motor neurons, CCINs, and unidentified gray matter neurons but has no effect on responses to AMPA (Parker et al., 1998). Although caution has to be exercised in extrapolating responses evoked by pressure application to events at the synaptic level, the failure of substance $\mathrm{P}$ to potentiate the mEPSP amplitude in every experiment could be explained by the absence of a significant NMDA component to these inputs, and thus, the lack of a substrate for the substance P-mediated postsynaptic modulation. The requirement of the NMDA component of the synaptic input for the postsynaptic potentiation of glutamatergic synaptic transmission was examined in three ways. First, in experiments in which the amplitude of the mEPSP was potentiated ( $n=5$ of 8 ), substance $\mathrm{P}$ also increased the half-decay time of the mEPSPs (Fig. $3 A ; p<0.05$ ), an effect consistent with the potentiation of the slow NMDA component of the synaptic potential (Dale and Grillner, 1986). Second, in experiments in which the mEPSP amplitude was not potentiated by substance $\mathrm{P}(n=3$ of $5)$, the NMDA receptor antagonist AP5 (100 $\mu \mathrm{M})$ also failed to affect the mEPSP amplitude [data not shown; $\mathrm{Q}_{\mathrm{KS}}(\lambda)>0.05$ ], suggesting that these mEPSPs lacked an NMDA component. Finally, the role of NMDA receptors was examined directly by applying substance P in the presence of AP5 (100 $\mu \mathrm{M})$. Substance $\mathrm{P}$ consistently failed to potentiate the mEPSP amplitude in these experiments (Fig. $3 B ; n=4$ of $4 ; \mathrm{Q}_{\mathrm{KS}}(\lambda)>0.05$ ), whereas the mEPSP frequency was again consistently increased (Fig. $3 C ; n=$ 4 of $\left.4 ; \mathrm{Q}_{\mathrm{KS}}(\lambda)<0.01\right)$. These effects, thus, support the results obtained with pressure application of NMDA and AMPA (Parker et al., 1998), which suggest that substance P postsynaptically potentiates glutamatergic synaptic inputs through a specific effect on the NMDA component of the synaptic potential.

An increase in mEPSP frequency, which presumably occurs as a result of the presynaptic potentiation of transmitter release, can be calcium-dependent or calcium-independent in different sys- 
Ai
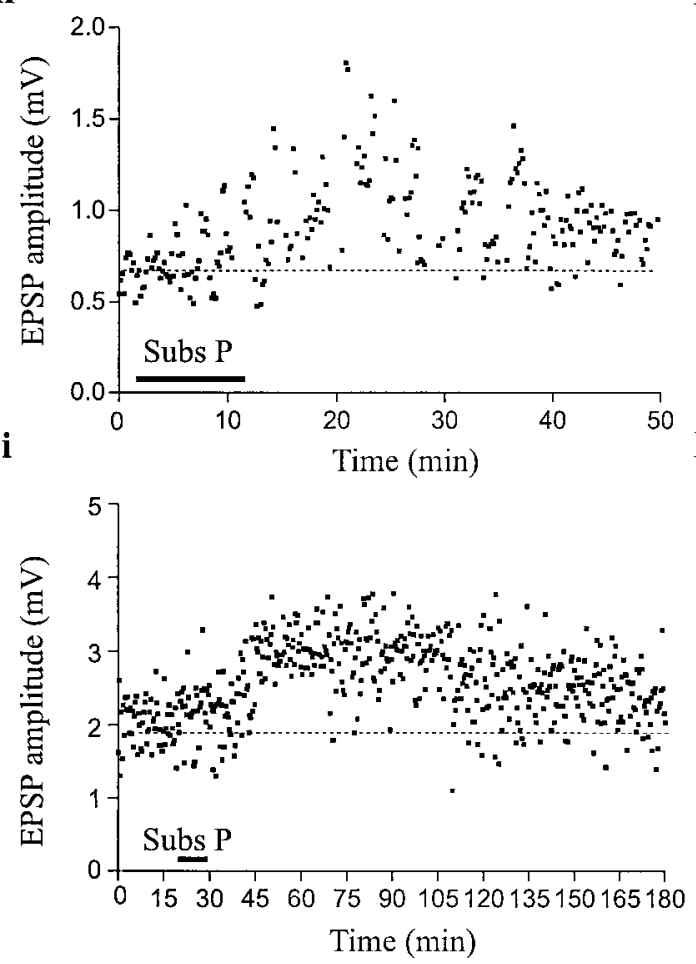

Ci



D

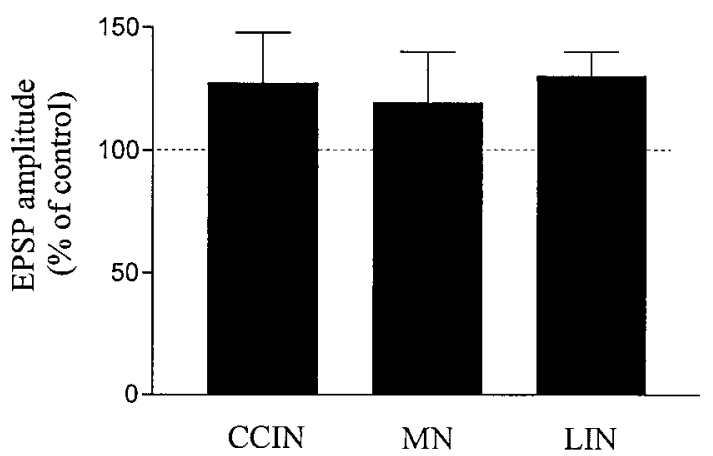

Aii

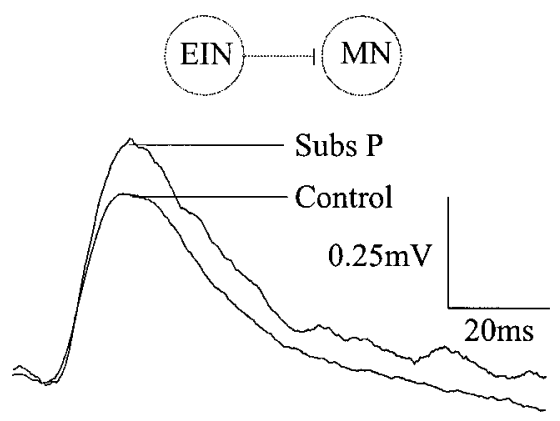

Bii

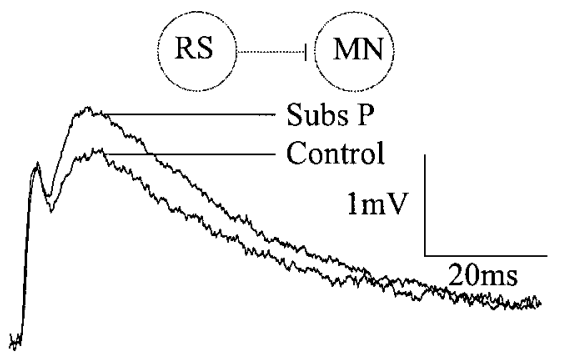

Cii
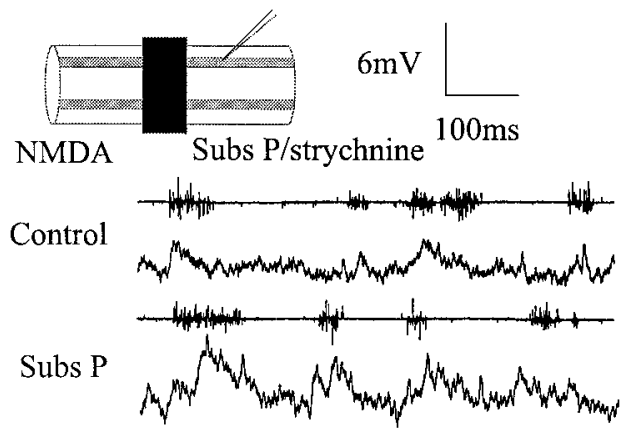

E

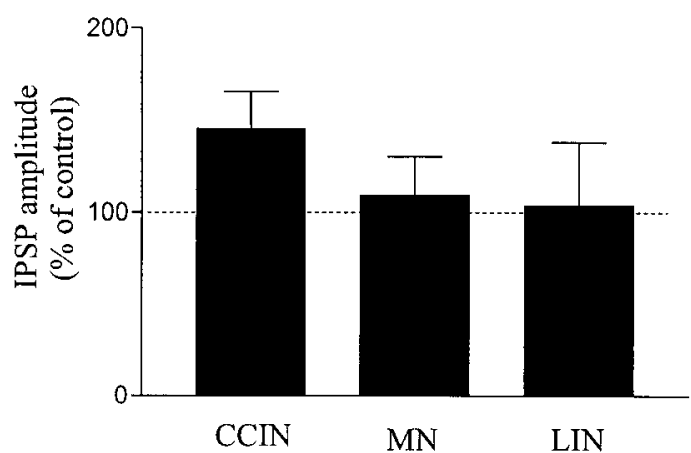

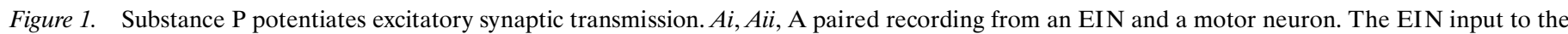





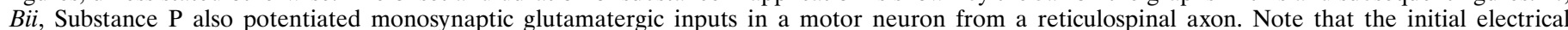

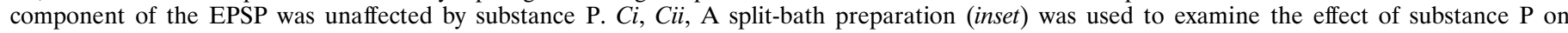

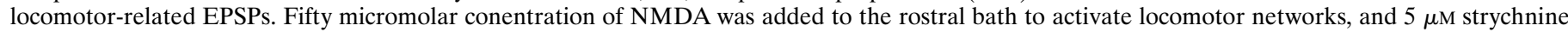

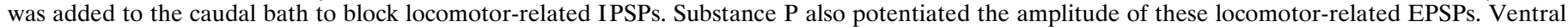

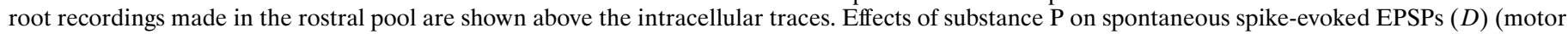

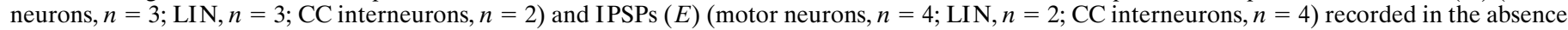
of TTX. 


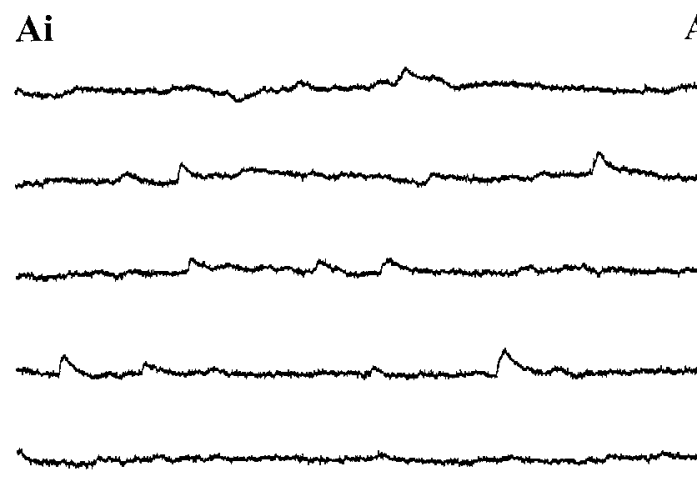

Aii


Figure 2. Substance P increased the amplitude and frequency of mEPSPs. mEPSPs were recorded in the presence of TTX (1.5 $\mu \mathrm{M})$ and strychnine (5 $\mu \mathrm{M})$. The frequency was calculated by measuring the interval between successive mEPSPs. $A i$, $A i i$, Sample traces of mEPSPs in control and in the presence of substance P. Histograms $(B i, C i)$ and cumulative probability plots (Bii, Cii) are shown for the amplitude and frequency of the mEPSPs in control and in the presence of substance P. The shift in the amplitude cumulative probability to the right in Bii indicates an increase in the number of large amplitude mEPSPs, whereas a shift in the curve to the left in Cii indicates an increase in the number of shorter intervals between mEPSPs. The histograms and cumulative probability plots are from different representative motor neurons.

tems (Parfitt and Madison, 1993; Capogna et al., 1995). The calcium dependence of the increase in mEPSP frequency was examined by applying substance $\mathrm{P}$ in the presence of the calcium channel antagonist cadmium $(200 \mu \mathrm{M})$. Cadmium did not prevent the increase in mEPSP frequency (Fig. $3 D ; n=5$ of $5 ; \mathrm{Q}_{\mathrm{KS}}(\lambda)<$ $0.01)$, suggesting that this substance P-induced effect is mediated downstream of calcium entry. However, in experiments in which cadmium was applied after recovery of the initial effects of substance P in cadmium-free Ringer's solution $(n=2)$, the increase in frequency was less than in control $(70.5 \pm 4.5 \%$ of control; data not shown), suggesting that there may be a small calciumdependent component to the presynaptic modulation. In contrast to the effect on mEPSP frequency, cadmium $(200 \mu \mathrm{M})$ consistently blocked the postsynaptic potentiation of the mEPSP amplitude ( $n=4$ of 5; data not shown), presumably as a result of an antagonistic effect at the NMDA receptor (Asher and Nowak, 1988).

\section{Inhibitory synaptic transmission}

The above results show that substance $\mathrm{P}$ presynaptically and postsynaptically potentiates glutamatergic synaptic transmission. Modulation of inhibitory synaptic transmission could also contribute to the substance P-mediated network modulation (Grillner and Wallén, 1980; Hellgren et al., 1992; Wallén et al., 1992). 
A



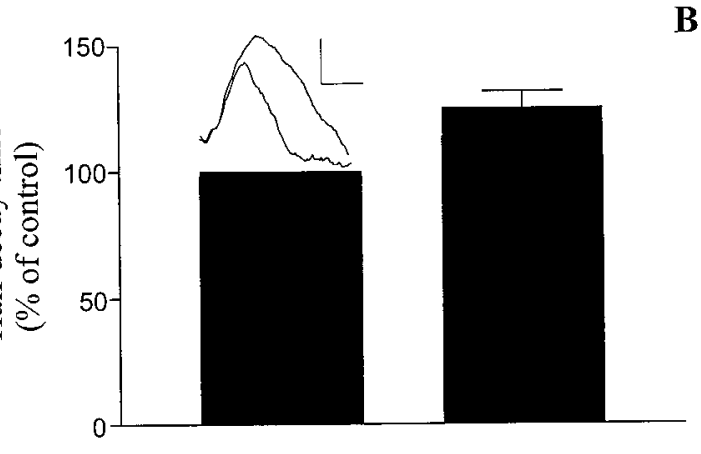

C

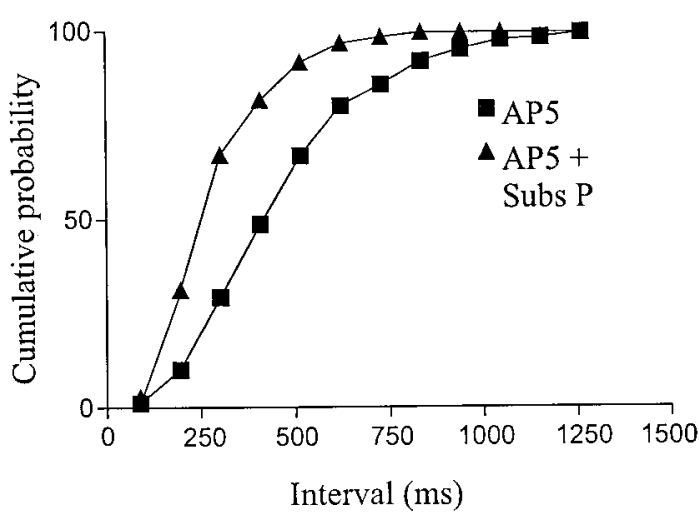

B

D
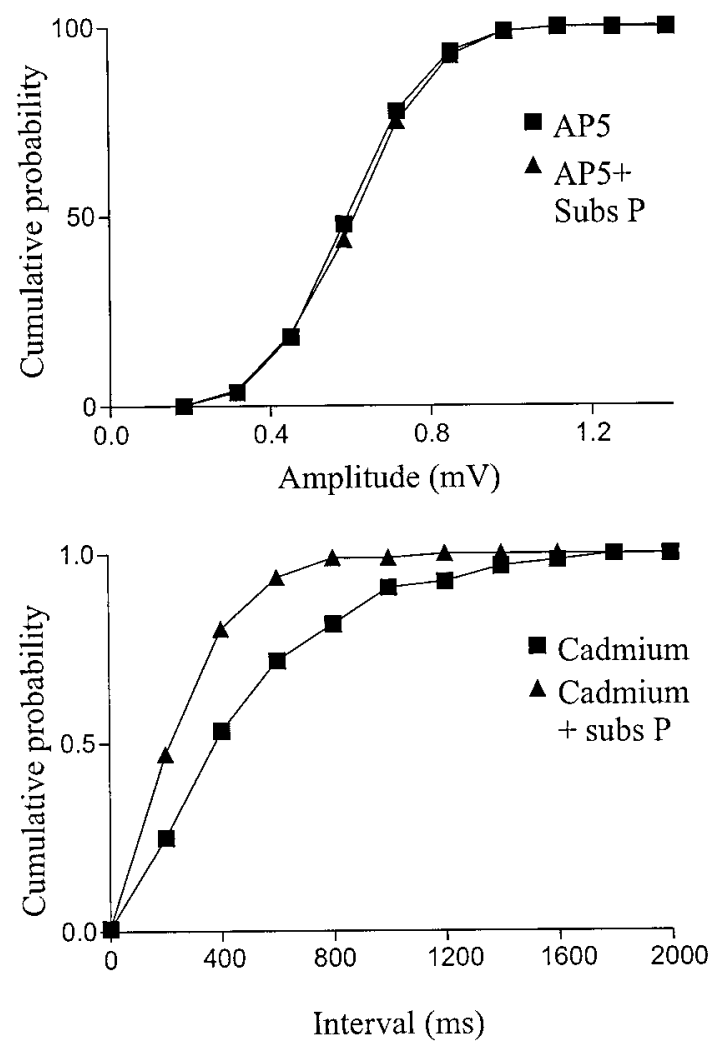

Figure 3. Properties of the increased amplitude and frequency of mEPSPs. $A$, The half-decay time of mEPSPs was increased in the presence of substance P. The inset shows averaged mEPSPs $(n=200)$ in control and in the presence of substance P. Calibration, inset: $0.25 \mathrm{mV}, 3 \mathrm{msec}$. $B$, The increased amplitude of the mEPSPs was blocked in the presence of the NMDA receptor antagonist AP5 (100 $\mu$ M). $C$, Blocking NMDA receptors with AP5 did not affect the increased frequency of the mEPSPs. $D$, The increase in mEPSP frequency was also not affected by the calcium channel antagonist cadmium $(200 \mu \mathrm{M})$, suggesting that the increased glutamate release was not calcium-dependent. Data from one neuron are shown in $B-D$.

The effects of substance $\mathrm{P}$ on inhibitory synaptic transmission were again initially examined by making paired recordings from identified network neurons.

The effect of substance $\mathrm{P}$ on reciprocal inhibition was examined by making paired recordings from inhibitory CCINs and contralateral motor neurons $(n=4)$ or unidentified gray matter neurons $(n=2)$. Substance $\mathrm{P}$ did not significantly affect glycinergic synaptic inputs from CCINs (Fig. $4 A ; n=5$ of $6, p>0.1$ ), the IPSP amplitude was reduced in only one cell, suggesting against an effect of substance $\mathrm{P}$ on reciprocal inhibitory inputs. Substance $\mathrm{P}$ also failed to affect monosynaptic glycinergic inputs from LINs to ipsilateral CCINs $(n=4$ of 5 ; Fig. $4 B)$ or monosynaptic glycinergic inputs from SiINs (Buchanan and Grillner, $1988)$ to lateral interneurons $(n=2)$ or motor neurons $(n=1$; Fig. $4 C$ ). Of the 11 pairs, seven were examined in high divalent cation Ringer's solution (see Materials and Methods). However, CCIN to motor neuron $(n=2)$ and LIN to CCIN $(n=2)$ pairs were also examined in normal Ringer's solution. In these cases, substance $\mathrm{P}$ again failed to affect the monosynaptic IPSP (data not shown), suggesting that the use of high divalent cation Ringer's solution did not occlude an effect of substance P on inhibitory synaptic inputs.

Although the above results suggested that substance P did not affect inhibitory synaptic transmission, locomotor-related and spontaneous IPSPs were examined to investigate the effect of substance P further. Locomotor-related IPSPs were examined using a split-bath preparation (see Materials and Methods).
NMDA $(50 \mu \mathrm{M})$ was added to the rostral pool to elicit locomotorrelated inhibitory inputs, which were recorded in motor neurons $(n=2)$ and unidentified gray matter neurons $(n=2)$ in the caudal pool. Normal Ringer's solution was added to the caudal pool, together with kynurenic acid $(1 \mathrm{~mm})$ to block excitatory synaptic inputs. Application of substance $\mathrm{P}$ to the caudal pool did not affect the amplitude of locomotor-related inhibitory inputs ( $n=3$ of 3 ; data not shown) but could transiently ( $<10 \mathrm{~min})$ reduce their frequency ( $n=2$ of 3 ), possibly because of an effect on the excitability of descending inhibitory neurons (see Fig. 10). Spontaneous mIPSPs were also examined. This was done in normal Ringer's solution with TTX $(1.5 \mu \mathrm{M})$ and either kynurenic acid $(1 \mathrm{~mm})$ or CNQX $(10 \mu \mathrm{M})$ and AP5 $(100 \mu \mathrm{M})$ present to block spike-evoked release and glutamatergic synaptic inputs, respectively (Fig. 5). The mean amplitude of the mIPSPs in control was $0.55 \pm 0.38 \mathrm{mV}$. Substance $P$ failed to affect the amplitude (Fig. 5Bi,Bii; $n=4$ of 5; mean amplitude, $0.57 \pm 0.43$ $\mathrm{mV}$ ) or frequency (Fig. $5 \mathrm{Ci}, \mathrm{Cii} ; n=5$ of 5 ) of mIPSPs in motor neurons $(n=3)$ or unidentified gray matter neurons $(n=2$; Fig. $\left.5 ; \mathrm{Q}_{\mathrm{KS}}(\lambda)>0.05 ; n=5\right)$.

These results thus suggest a lack of effect of substance $P$ on glycinergic synaptic inputs. One preliminary result, however, suggests that specific glycinergic inputs may be modulated. This was shown by examining the effects of substance $\mathrm{P}$ on spontaneous, spike-evoked IPSPs recorded in the presence of $1 \mathrm{~mm}$ kynurenic acid to block glutamatergic inputs but without the addition of 
Ai

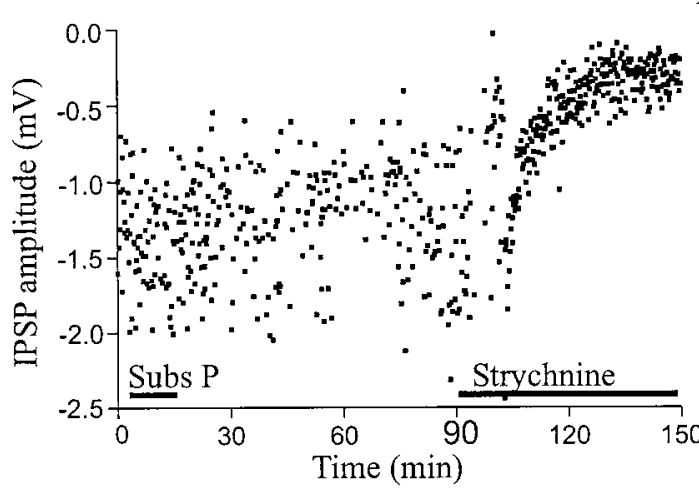

Bi

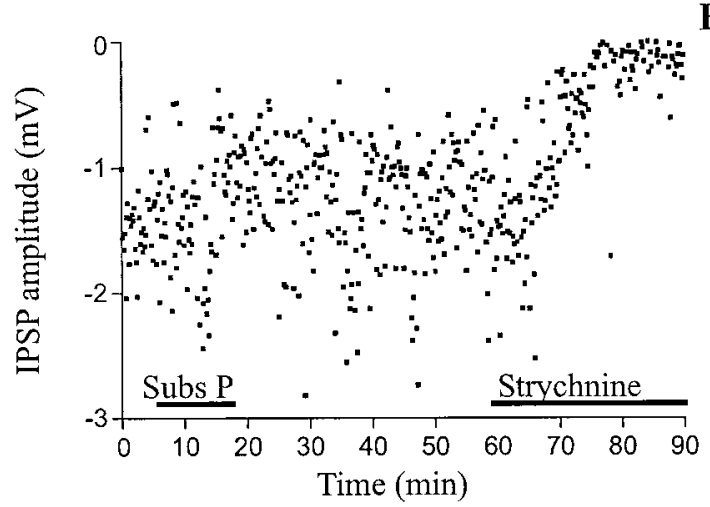

Aii

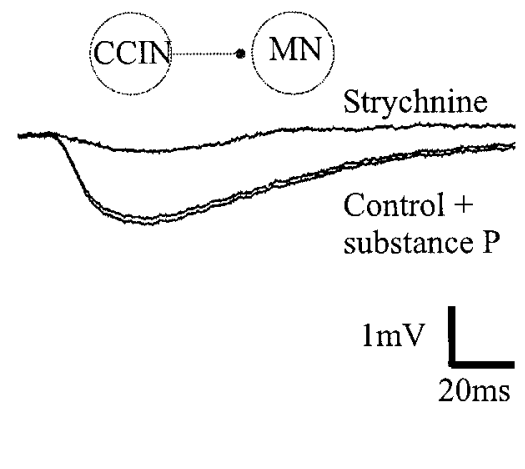

Bii

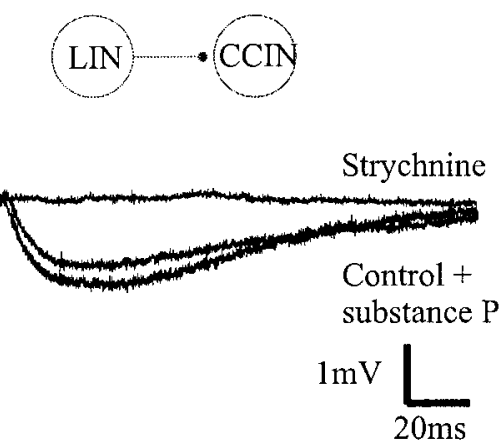

\section{$\mathbf{C i}$}

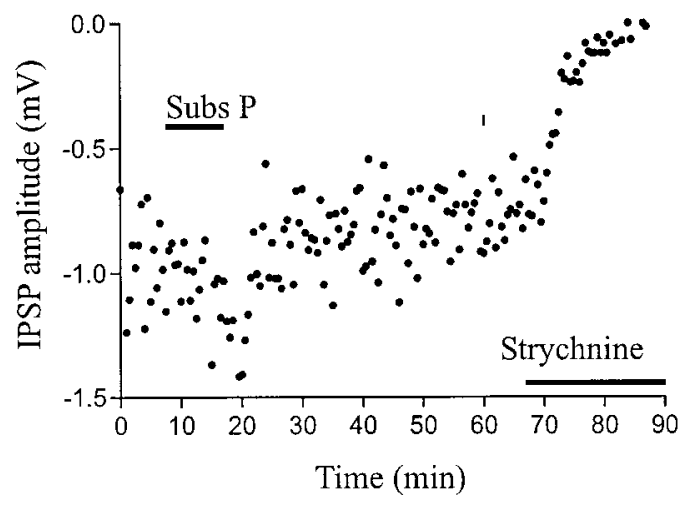

Cii

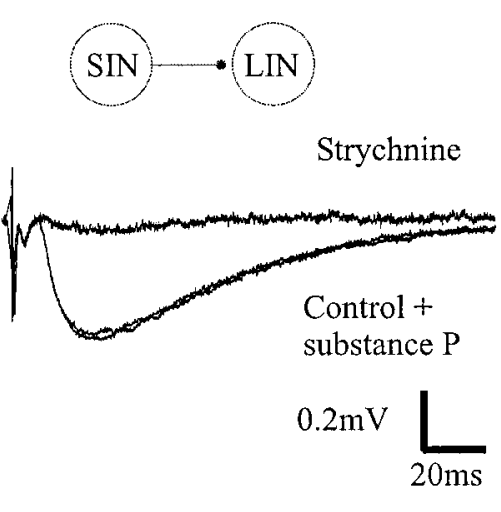

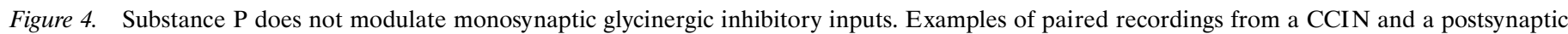

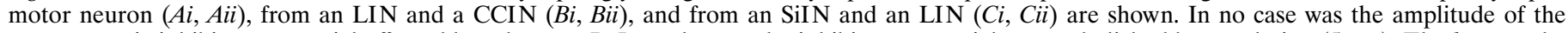

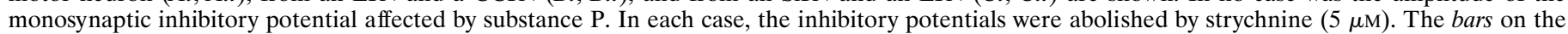
graph indicate the onset and duration of substance $\mathrm{P}$ and strychnine application.

TTX. Although the amplitude of spontaneous IPSPs was not affected in either motor neurons $(n=4)$ or LINs $(n=2$; Fig. $1 E)$, the amplitude of these inputs tended to increase in CCINs (Fig. $1 E ; n=3$ of 4 ), suggesting that specific inhibitory inputs to these cells may be modulated. The increased amplitude of spontaneous IPSPs in CCINs recovered to control after washing for 40-90 $\mathrm{min}$.

\section{Effects of substance P on GABAergic responses}

In addition to glycine, presynaptic and postsynaptic inhibition in the lamprey spinal cord is also mediated by GABA (Alford et al., 1991; Matsushima et al., 1993; Tegnér et al., 1993). GABAergic neurons have been shown to be present in the gray matter region of the spinal cord in which motor neurons and network interneu- rons have their somata (Brodin et al., 1990). Because of their small somata, paired recordings are difficult to make from these neurons. To examine the effects of substance $\mathrm{P}$ on postsynaptic GABA responses, GABA (1 $\mathrm{mm}$ ) was applied using pressure (pulse duration, 20-200 msec) onto the surface of the spinal cord above the impaled neuron. TTX $(1.5 \mu \mathrm{M})$ was used to block indirect effects caused by the action of GABA on nearby neurons. GABA resulted in a hyperpolarization in motor neurons $(n=3)$ and unidentified network neurons $(n=4)$. The hyperpolarization had an initial fast component and a slower developing component (Fig. 6Ai). With the $\mathrm{GABA}_{\mathrm{A}}$ receptor agonist muscimol or the $\mathrm{GABA}_{\mathrm{B}}$ receptor agonist baclofen, only a fast or a slow response, respectively, was obtained (Fig. $6 A i$, Aiii). GABA $_{\mathrm{A}}$ responses 
Ai

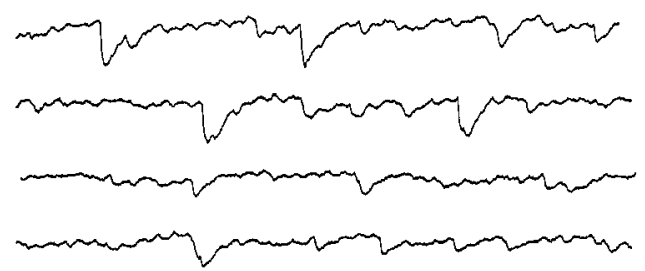

Control

Bi

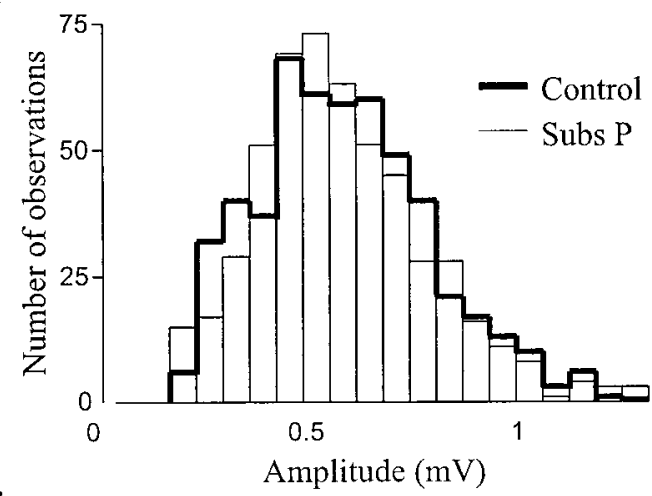

$\mathrm{Ci}$

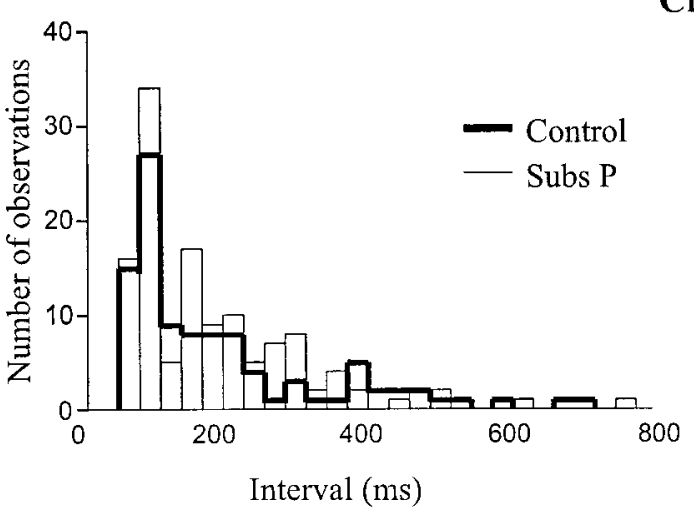

Aii

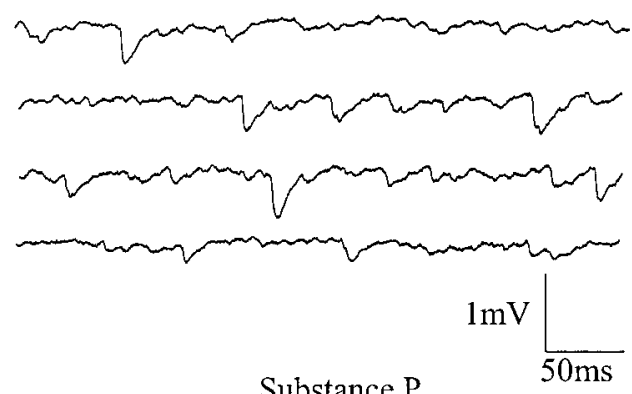

Substance P

Bii

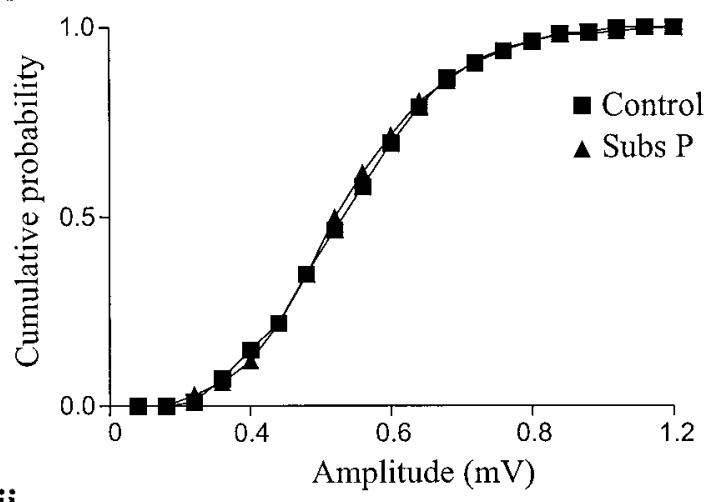

Cii

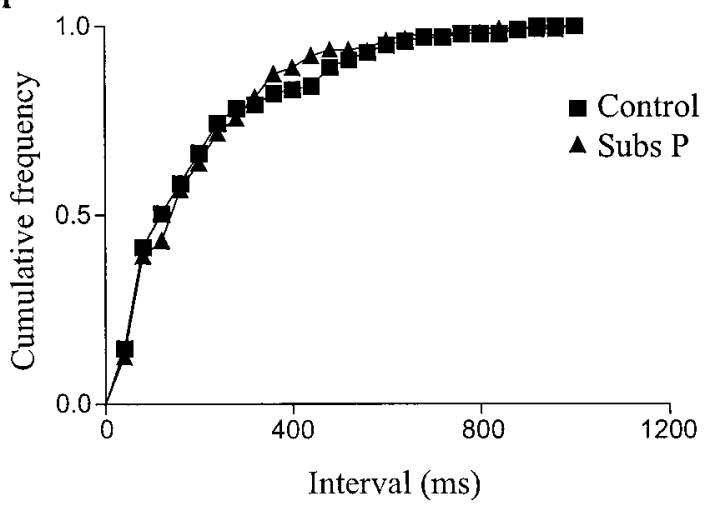

Figure 5. Substance P does not affect the amplitude or frequency of mIPSPs. mIPSPs were recorded in the presence of TTX (1.5 $\mu \mathrm{M})$ and either $1 \mathrm{mM}$ kynurenic acid or $100 \mu \mathrm{M}$ AP5 and $10 \mu \mathrm{M} \mathrm{CNQX}$, to block glutamatergic inputs. Ai, Aii, Sample traces showing mIPSPs in control and in the presence of substance P. Frequency histograms $(B i, C i)$ and cumulative probability plots $(B i i, C i i)$ are shown for the amplitude and frequency of the mIPSPs in control and in the presence of substance P. The frequency of mIPSPs was again calculated by measuring the interval between successive mIPSPs. Data from single representative neurons are shown, with separate neurons being used to provide histograms and cumulative probability plots.

were blocked by the $\mathrm{GABA}_{\mathrm{A}}$-receptor antagonist bicuculline (10 $\mu \mathrm{M})$, and $\mathrm{GABA}_{\mathrm{B}}$ responses were blocked by the $\mathrm{GABA}_{\mathrm{B}^{-}}$ receptor antagonists phaclofen $(1 \mathrm{mM})$ or CGP $35348(50 \mu \mathrm{M})$. In no experiment $(n=7)$ did substance $\mathrm{P}$ significantly affect the amplitude of the slow or fast component of the GABAergic response (Fig. $6 A i ; p>0.05$ ) or the amplitude of responses evoked by the $\mathrm{GABA}_{\mathrm{A}}$ and $\mathrm{GABA}_{\mathrm{B}}$ receptor agonists muscimol (200 $\mu \mathrm{M} ; n=2$; Fig. 6 Aii) and baclofen (1 mM; $n=3$; Fig. 6 Aiii $)$. $\mathrm{GABA}_{\mathrm{A}}$ or $\mathrm{GABA}_{\mathrm{B}}$ receptor activation also depolarizes spinal axons, an effect that contributes to presynaptic inhibition (Alford et al., 1991). In preliminary experiments on unidentified axons $(n=3)$, substance $\mathrm{P}$ also failed to affect the amplitude of axonal GABA responses (data not shown).

\section{Cellular effects of substance $\mathbf{P}$}

Bath application of substance $\mathrm{P}$ to the isolated spinal cord for 10 min increased synaptic inputs and caused membrane potential oscillations in motor neurons $(n=7$; Fig. $7 A)$, LINs $(n=5$; Fig. $7 B)$, CCINs $(n=4$; Fig. $7 C)$, and EINs $(n=5$; Fig. $7 D)$. When substance P was applied in the presence of TTX $(1.5 \mu \mathrm{M})$ to block spiking and, thus, spike-evoked transmitter release, substance $\mathrm{P}$ directly depolarized the membrane potential of the EINs (7.8 \pm $2.1 \mathrm{mV}$; Fig. 7Dii). Substance P also evoked a depolarization in motor neurons in the presence of TTX, although this was smaller than that in EINs $(\sim 2 \mathrm{mV}$; E. Svensson, unpublished observation). The oscillations were blocked by TTX, suggesting that they 


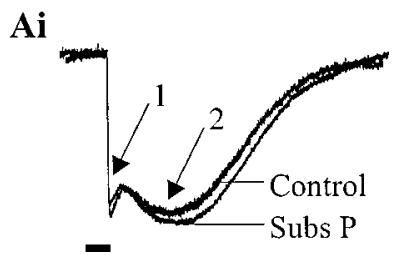

$\overline{\mathrm{GABA}}$

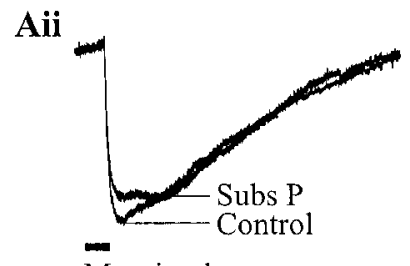

Muscimol

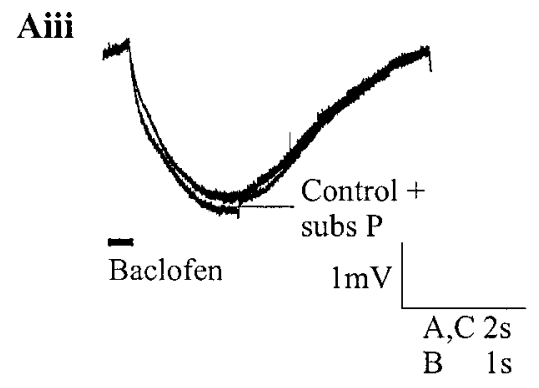

C

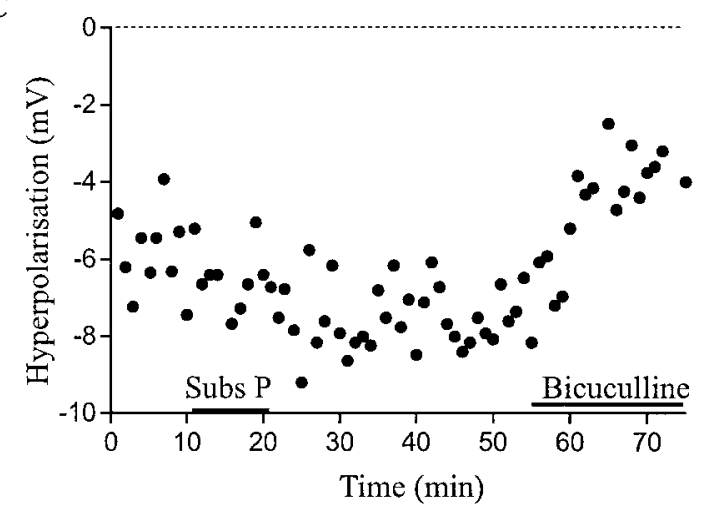

Figure 6. Substance P does not modulate GABAergic responses. Ai, Trace showing the effect of pressure application of GABA (1 mM; $200 \mathrm{msec}$ pulse duration) on a motor neuron. The GABA response had a fast and a slow component. Substance P did not affect either component of the GABA response. Aii, Trace showing the lack of an effect of substance $\mathrm{P}$ on responses to the $\mathrm{GABA}_{\mathrm{A}}$ receptor agonist muscimol $(200 \mu \mathrm{M})$. Aiii, Trace showing the lack of an effect of substance $\mathrm{P}$ on responses to the $\mathrm{GABA}_{\mathrm{B}}$ receptor agonist baclofen $(1 \mathrm{~mm})$. Graphs showing the effect of substance $\mathrm{P}$ on the fast $(B)$ and slow $(C)$ GABA responses elicited in the neuron shown in $A i$ (1 and 2 refer to the fast and slow components, respectively). Substance P did not affect either component. The $\mathrm{GABA}_{\mathrm{A}}$ receptor antagonist bicuculline blocked the fast component, whereas the slow component persisted. The reduction in the amplitude of the slow component may have been caused by it developing from the baseline, as opposed to a relatively hyperpolarized level when the bicuculline-sensitive component was present.

were not caused by the activation of intrinsic conductances. The TTX-sensitive oscillations were irregular and consisted of shortor long-lasting ( $\sim 2 \mathrm{~min}$ ) plateau-like depolarizations, followed by hyperpolarized periods. Spiking was usually only evoked in motor neurons ( $n=5$ of 7$)$ and EINs $(n=3$ of 5$)$. The peak depolarization, measured as the most depolarized membrane potential reached (excluding spikes) was greater in EINs than in any other type of neuron (Fig. $1 F ; p<0.05$, one-way ANOVA). In contrast to the effect on the peak depolarization, the number of oscillations (measured in a $10 \mathrm{~min}$ period after the first oscillation occurred) was significantly less in EINs than in any other type of neuron (Fig. 7G; $p<0.05$, one-way ANOVA). The number and amplitude of oscillations was not significantly different between motor neurons, LINs, or CCINs ( $p>0.05$, one-way ANOVA). The membrane potential oscillations recovered after washing for $16.7 \pm 2.9 \mathrm{~min}$ in motor neurons, $8.7 \pm 4.8 \mathrm{~min}$ in LINs, and $11.5 \pm 4.2 \mathrm{~min}$ in EINs, but required a significantly longer wash time in CCINs $(30.6 \pm 13 \mathrm{~min} ; p<0.05$, one-way ANOVA). The increase in synaptic inputs, shown by the thickened baseline, usually outlasted the membrane potential oscillations (recovery time: motor neurons, $25 \pm 5.6 \mathrm{~min}$; LINs, $14 \pm 7.9 \mathrm{~min}$; CCINs, $42 \pm 18.5 \mathrm{~min}$; and EINs, $23.3 \pm 5.2 \mathrm{~min}$ ), the effect in CCINs again being significantly longer than in the other cell types $(p<$ 0.05 , one-way ANOVA). The tachykinin agonist neurokinin A (1 $\mu \mathrm{M}$ for $10 \mathrm{~min})$ also evoked membrane potential oscillations $(n=$ 3 unidentified neurons; Fig. 7E).

Substance $P$ activates descending excitatory neurons

EINs are among the smallest neurons in the spinal cord (Buchanan and Grillner, 1987), thus making it difficult to obtain stable long-lasting recordings from these cells. The effect of substance $\mathrm{P}$ on the activity of descending excitatory propriospinal neurons, presumably including the EINs, was analyzed further by using a split-bath preparation (see Materials and Methods). Substance P was applied to the rostral pool, whereas intracellular recordings were made from neurons in the caudal pool. Substance $\mathrm{P}$ increased the amplitude and frequency of synaptic inputs to motor neurons $(n=2)$ and unidentified neurons $(n=3)$ in the caudal pool (Fig. $8 A, B$ ). This synaptic input was predominantly depolarizing and was sufficient to cause the cell to spike when the application of substance $\mathrm{P}$ was continued for $20 \mathrm{~min}(n=4)$. When glycinergic inputs were blocked by adding strychnine (5 $\mu \mathrm{M})$ to the caudal pool, the descending input elicited large depolarizations and bursts of action potentials in caudal pool neurons $(n=4$; Fig. $8 C)$. Application of the excitatory amino acid antagonist kynurenic acid ( $1 \mathrm{~mm}$ ) to the caudal pool blocked the effects of substance $\mathrm{P}$ application to the rostral pool $(n=3$; data not shown). There was no noticeable increase in IPSPs in the caudal pool in the presence of kynurenic acid, presumably because of the inhibitory effect of substance $\mathrm{P}$ on descending inhibitory neurons (see Fig. $10 D, E$ ). These results suggest that substance $\mathrm{P}$ excites descending excitatory neurons. In addition to EINs, these neurons could include excitatory CCINs (Buchanan, 1982) and descending branches of afferent axons (Christenson et al., 1988; Zhang et al., 1996), both of which project caudally for several segments. The latter input is particularly relevant because substance $\mathrm{P}$ excites afferent neurons, shown by the spiking recorded extracellularly from the dorsal root or dorsal column $(n=3$ of 3 ; Fig. 8D). 


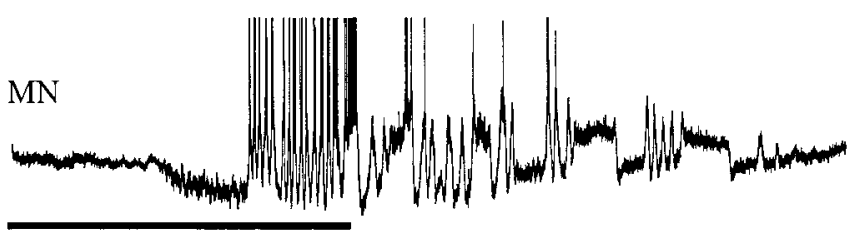

Substance P

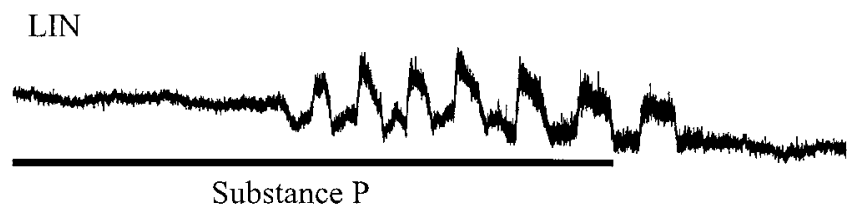

Di

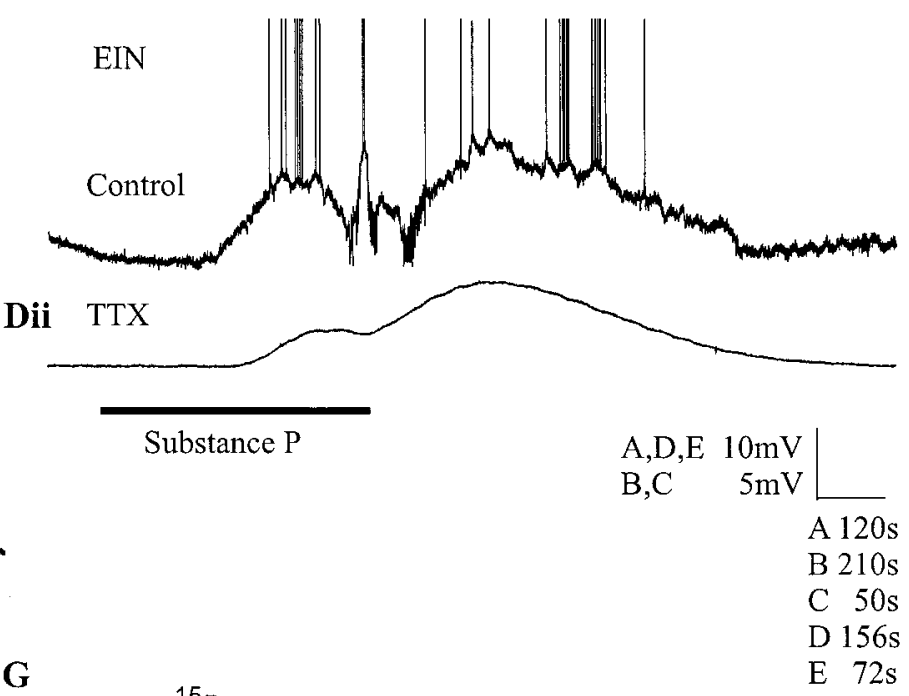

F

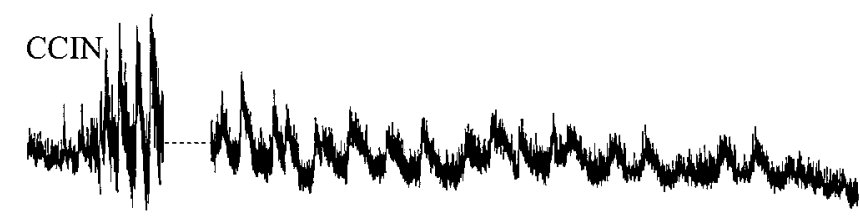

Substance P

$\mathrm{E}$

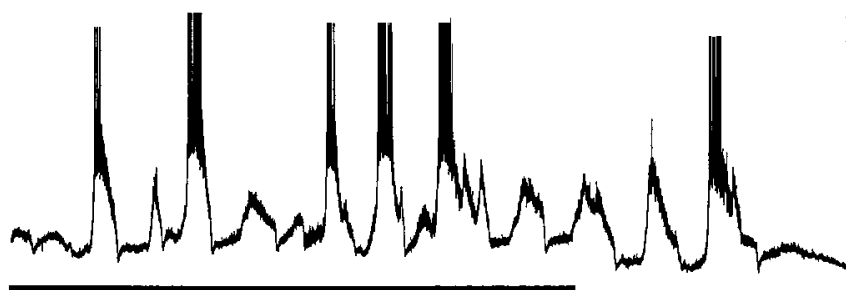

NKA

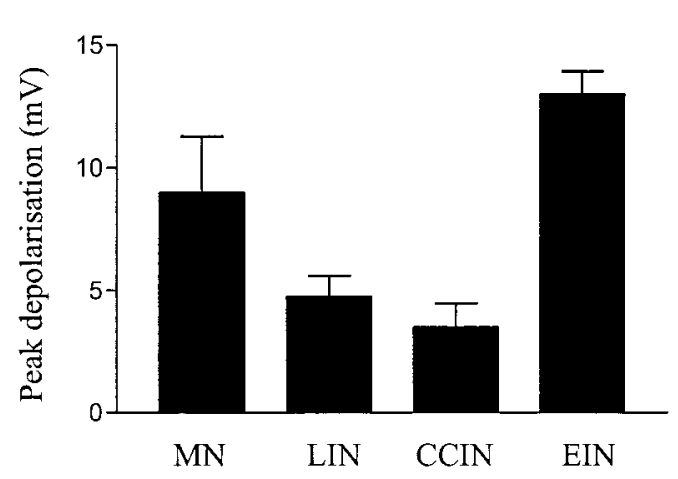

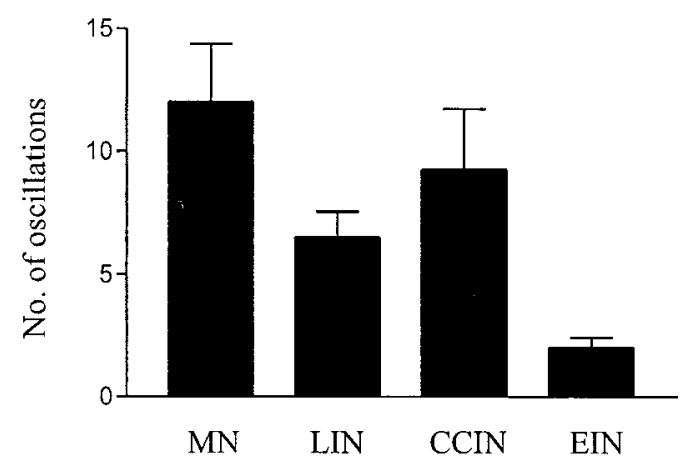

Figure 7. Substance $\mathrm{P}$ increases synaptic inputs and elicits membrane potential oscillations in network neurons. Representative effects of substance $\mathrm{P}$ on a motor neuron $(A)$, an LIN $(B)$, a CCIN $(C)$, and an EIN $(D)$. The EIN was examined in normal Ringer's solution $(D i)$ and in the presence of TTX $(1.5 \mu \mathrm{M} ; \mathrm{Dii}) . E$, The tachykinin agonist neurokinin A $(1 \mu \mathrm{M})$ also induced membrane potential oscillations and spiking in unidentified neurons. The onset and duration $(10 \mathrm{~min})$ of drug application is shown by the bar underneath each figure. The spikes are clipped in $A, D$, and $E$. F, $G$, Graphs showing the effects of substance $\mathrm{P}$ on the amplitude and number of oscillations in motor neurons $(n=7)$, LINs $(n=5)$, CCINs $(n=4)$, and EINs $(n=5)$. The amplitude was measured from the baseline preceding the onset of the substance $\mathrm{P}$ effects to the peak depolarization (excluding spikes), and the frequency by the number of oscillations that occurred in the first 10 min after substance $\mathrm{P}$ application.

\section{Effect of substance $P$ on the input resistance of} network neurons

Substance $\mathrm{P}$ did not have a significant effect on the input resistance of motor neurons $(n=14)$, LINs $(n=5)$, CCINs $(n=8)$, or EINs ( $n=8$, Fig. 9; $p>0.1$, one-way ANOVA). This was measured by injecting $100 \mathrm{msec}$ hyperpolarizing current pulses into the somata at the same membrane potential in control and after substance $\mathrm{P}$ application. Because substance $\mathrm{P}$ has a direct depolarizing effect on the membrane potential of motor neurons (Svensson, unpublished observation) and EINs (Fig. 7Dii), the lack of an effect on the input resistance suggests that the substance P-induced depolarization is not caused by an increase or decrease of a single conductance. Substance P has previously been shown to depolarize lamprey mechanosensory neurons through both an increase and decrease of membrane conductances (Parker and Grillner, 1996).

\section{Effects of substance $P$ on spiking in network neurons}

The effect of substance $\mathrm{P}$ on spiking in identified spinal neurons was examined by injecting $100 \mathrm{msec}$ depolarizing current pulses into their somata (see Materials and Methods). Cells were examined in current clamp at the same membrane potential in control and in the presence of substance P. AP5 $(100 \mu \mathrm{M})$, CNQX (10 $\mu \mathrm{M})$, and strychnine $(5 \mu \mathrm{M})$, were used to block synaptic inputs. 
A

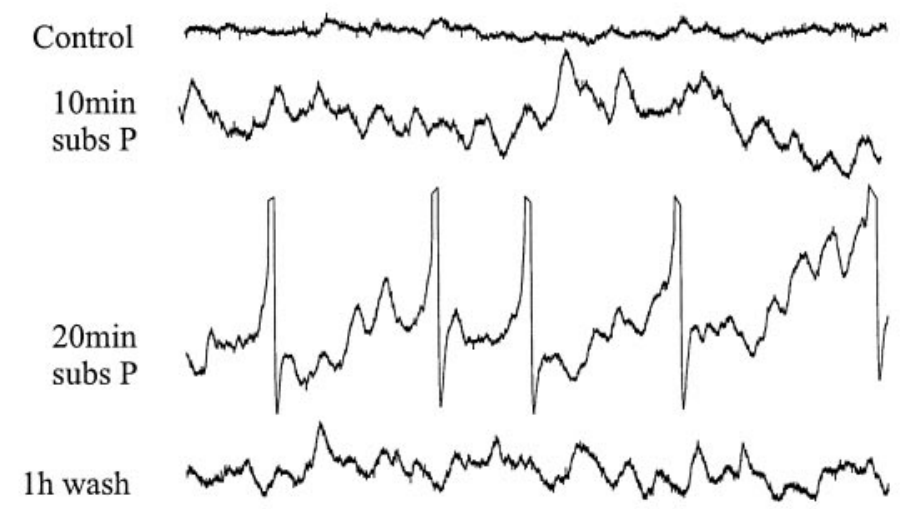

C
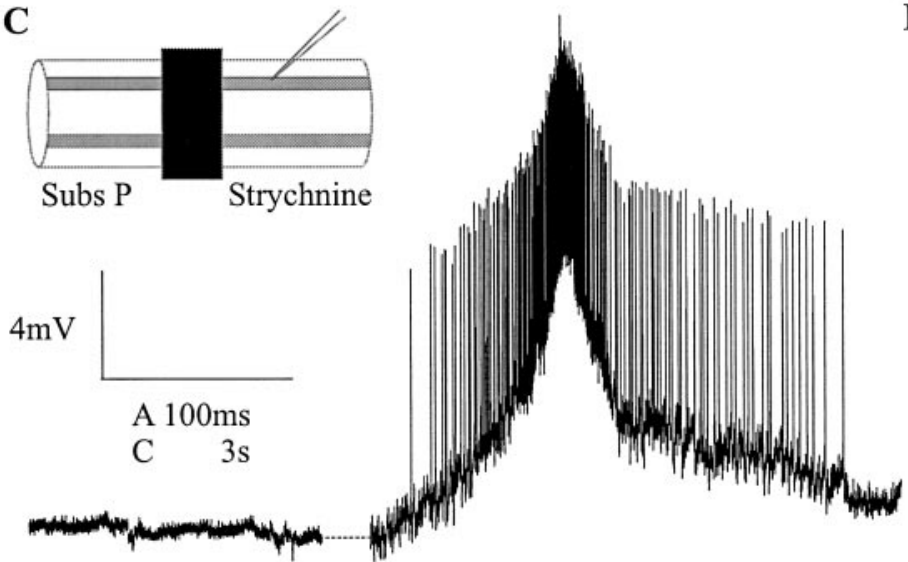

B

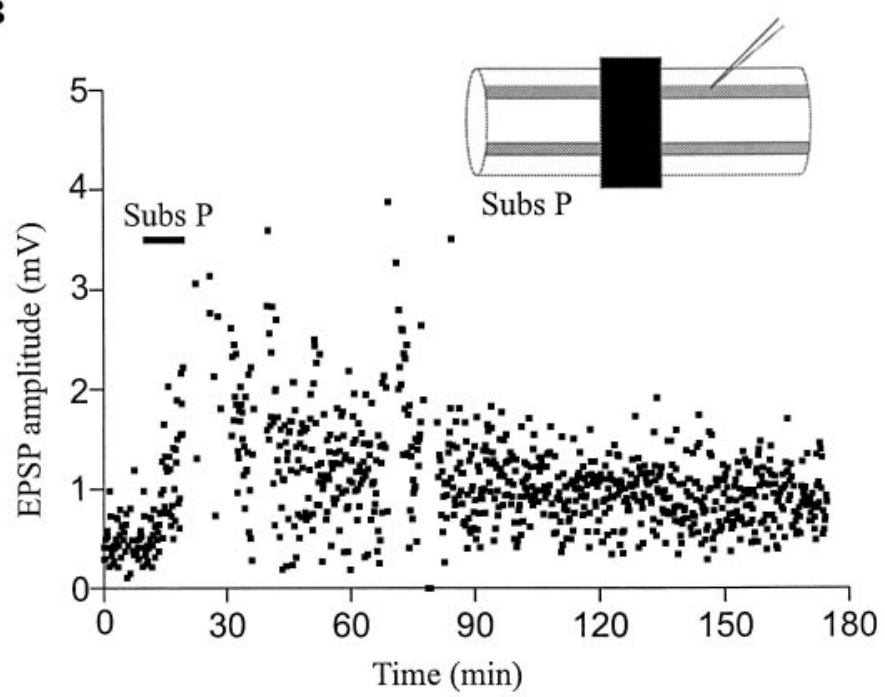

D

$10 \mathrm{~min}$

substance $\mathrm{P}$

Figure 8. Substance $\mathrm{P}$ increases descending excitatory inputs. A split-bath preparation was used to examine the effects of substance $\mathrm{P}$ on descending excitatory neurons. A Vaseline barrier was built to separate the spinal cord into two pools $(B$, inset $)$. Substance $\mathrm{P}$ was added to the rostral pool. Neurons were impaled in the caudal pool within five segments of the barrier. $A$, The effect of substance $\mathrm{P}$ application to the rostral pool when the caudal pool contained normal Ringer's solution. The spikes have been clipped. $B$, Graph showing the potentiation of the amplitude of excitatory synaptic inputs by rostral application of substance $\mathrm{P}(n=4)$. $C$, The effects of substance $\mathrm{P}$ when $5 \mu \mathrm{M}$ strychnine was added to the caudal pool. Recordings in $A$ and $C$ are from unidentified gray matter neurons recorded in different experiments. $D$, Extracellular recording from the dorsal root and dorsal column in an isolated spinal cord preparation. A split-bath preparation was not used in these experiments. Substance P caused spiking in dorsal root and dorsal column axons, suggesting that it excites primary afferent axons. The bar indicates the onset and duration (10 min) of substance $\mathrm{P}$ application.

Application of substance $\mathrm{P}$ for $10 \mathrm{~min}$ increased the number of spikes evoked by depolarizing current pulses in motor neurons $(n=12$ of 14 ; Fig. $10 A ; p<0.05)$, LINs $(n=4$ of 5 ; Fig. $10 B ; p<$ $0.05)$, and EINs ( $n=6$ of 8 , Fig. $10 C ; p<0.05)$. The effect on CCINs was more variable, with a reduction seen in four cells, no effect in three, and an increase in one (Fig. 10D; $p>0.05$ ). This variability may reflect the presence of different subtypes of CCINs (Buchanan, 1982). Substance P also affected the latency from the onset of the current pulse to the first spike, a reduction being seen in motor neurons $(n=12)$, LINs $(n=4)$, and EINs $(n=6)$, and an increase in CCINs $(n=6$ of 8 ; Fig. $10 E)$. These effects on spiking had largely recovered to control after washing for $1 \mathrm{hr}$ (motor neuron, LIN, and CCIN; $p<0.1$ ). It was not possible to keep EIN recordings for long enough to examine recovery of the effects of substance $\mathrm{P}$ after washing for $1 \mathrm{hr}$.

A 5-HT-mediated increase in spiking in motor neurons and LINs is associated with a reduction of the $\mathrm{AHP}_{\mathrm{Ca}}$ (Wallén et al.,
1989). Substance $\mathrm{P}$ significantly reduced the $\mathrm{AHP}_{\mathrm{Ca}}$ in motor neurons $(n=12$ of $14 ; p<0.05)$ and LINs $(n=4$ of 5; Fig. $11 A$; $p<0.05)$. This reduction of the $\mathrm{AHP}_{\mathrm{Ca}}$ may account for the increased number of spikes evoked in the presence of substance P. The $\mathrm{AHP}_{\mathrm{Ca}}$ was not significantly affected in CCINs $(n=6$ of 8; Fig. $11 A ; p>0.1)$ or EINs ( $n=6$ of 8 ; Fig. $11 A ; p>0.05)$. In these cells, in both cases in which an effect was seen on $\mathrm{AHP}_{\mathrm{Ca}}$, it was a reduction of the amplitude. The $\mathrm{AHP}_{\mathrm{Ca}}$ in motor neurons and LINs recovered after washing for $1 \mathrm{hr}(p>0.05)$. The calcium-independent early afterhyperpolarization (Fig. 11B), spike amplitude (Fig. 11C), and spike duration were not significantly affected by substance $\mathrm{P}$ in any type of network neuron $(p>0.1$; Fig. 11D).

\section{DISCUSSION}

Several cellular and synaptic effects of substance $\mathrm{P}$ that could contribute to the modulation of the locomotor network (Parker et 
A

MN

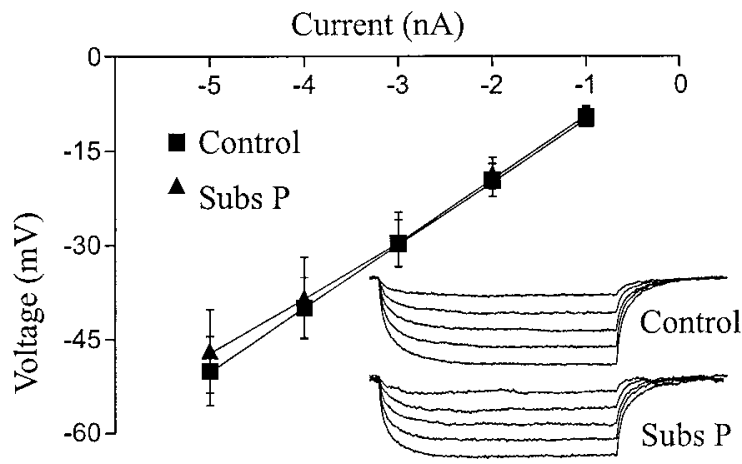

C

CCIN

Current (nA)

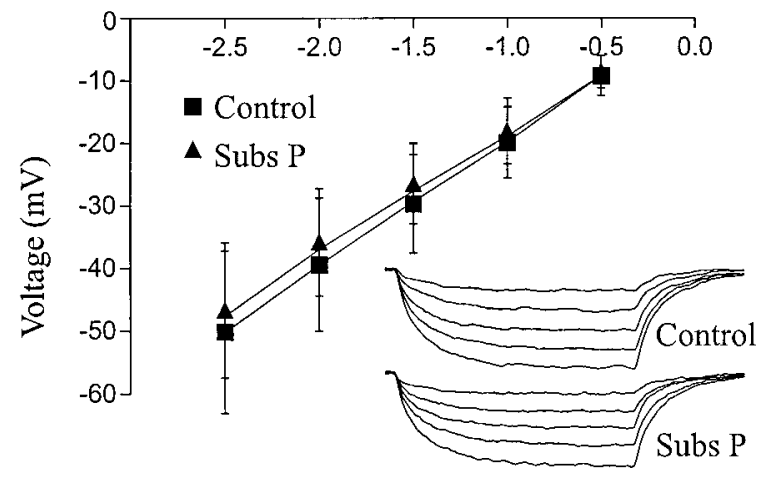

B

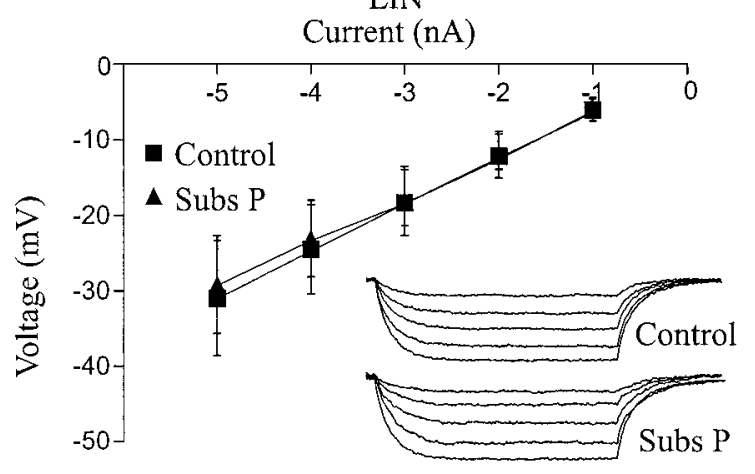

D

EIN

Current (nA)

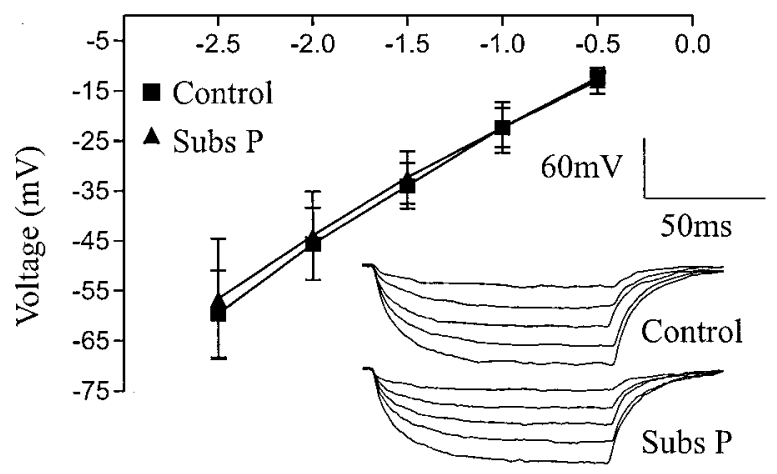

Figure 9. Substance $\mathrm{P}$ does not significantly affect the input resistance of motor neurons $(A)$, LINs $(B)$, CCINs $(C)$, or EINs $(D)$. The input resistance was examined by injecting $100 \mathrm{msec}$ hyperpolarizing current pulses using single electrode current clamp. The membrane potential was held at the same membrane potential $(-70 \mathrm{mV})$ in control and in the presence of substance P. Kynurenic acid $(1 \mathrm{mM})$ and strychnine $(5 \mu \mathrm{M})$ were used to block synaptic inputs to the cells. Data from 14 motor neurons, 5 LINs, 8 CCINs, and 8 EINs are shown.

al., 1998) have been identified in this paper (Fig. 12). Substance $\mathrm{P}$ potentiates glutamatergic inputs from EINs and reticulospinal axons, but has little effect on inhibitory synaptic transmission from LINs, CCINs, or SiINs. At the cellular level, substance P increases the spiking in response to depolarizing current pulses in motor neurons, LINs, and EINs but reduces it in CCINs.

\section{Synaptic effects of substance $P$}

Substance $\mathrm{P}$ potentiated monosynaptic glutamatergic inputs. The amplitude and frequency of spontaneous mEPSPs were increased, suggesting that the synaptic modulation occurs presynaptically and postsynaptically. Because of the relatively large noise levels with sharp electrodes, it is not possible to say whether the mEPSPs were the smallest (i.e., quantal) values or just the smallest responses that could be measured above the noise. It could thus be argued that the increased frequency of mEPSPs was caused by an increase in the amplitude of responses that were previously hidden in the baseline noise. This seems unlikely, however, because the increased mEPSP frequency occurred independently of an effect on the mEPSP amplitude (Fig. 3B,C). The increased mEPSP amplitude was caused by a specific effect of substance $\mathrm{P}$ on the NMDA component of the synaptic potential, supporting results that showed that substance $\mathrm{P}$ acts through protein kinase $\mathrm{C}$ to potentiate pressure-applied NMDA, but not AMPA, responses (Parker et al., 1998). The increased mEPSP frequency persisted in the presence of cadmium, suggesting that the effect on transmitter release is largely calcium-independent.

In contrast to the effect on glutamatergic inputs, substance $\mathrm{P}$ did not affect monosynaptic or spontaneous glycinergic IPSPs, or postsynaptic responses to pressure-applied GABA, suggesting against an effect on inhibitory synaptic transmission. However, preliminary results suggest that specific inhibitory inputs to CCINs may be modulated (Fig. $1 E$ ). Because LIN inputs to CCINs were not affected by substance $\mathrm{P}$, the source of this input is currently unknown. Potential sources include contralateral CCINs (Buchanan, 1982), small segmental contralateral or ipsilateral glycinergic neurons (Buchanan and Grillner, 1988; Ohta et al., 1991), or GABAergic neurons (Safronov et al., 1989; Brodin et al., 1990).

\section{Cellular effects of substance $P$}

Substance $\mathrm{P}$ increased synaptic inputs and caused membrane potential oscillations in motor neurons, CCINs, LINs, and EINs. The membrane potential oscillations do not result from intrinsic conductances in the network neurons, but are instead synaptically generated by the activation of network neurons. This has been shown in motor neurons (Svensson, unpublished observation) and EINs (Fig. 1D), in which substance P only evokes a depolarization, but no oscillations, in the presence of TTX. In addition, no oscillations were evoked in motor neurons or CCINs when 
A

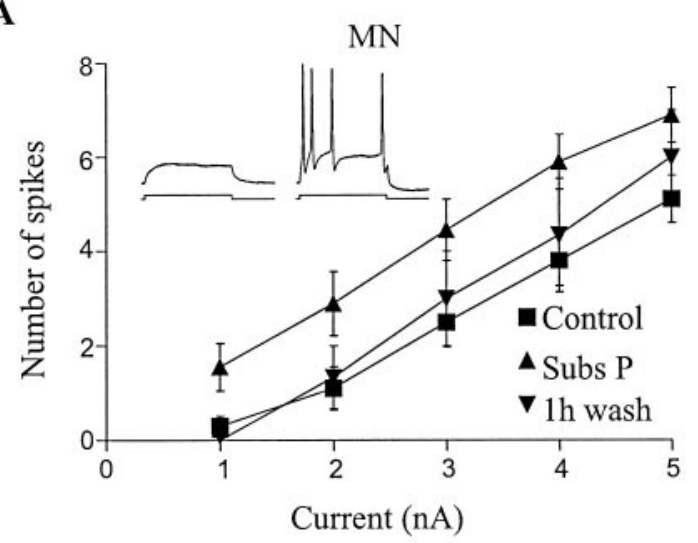

C

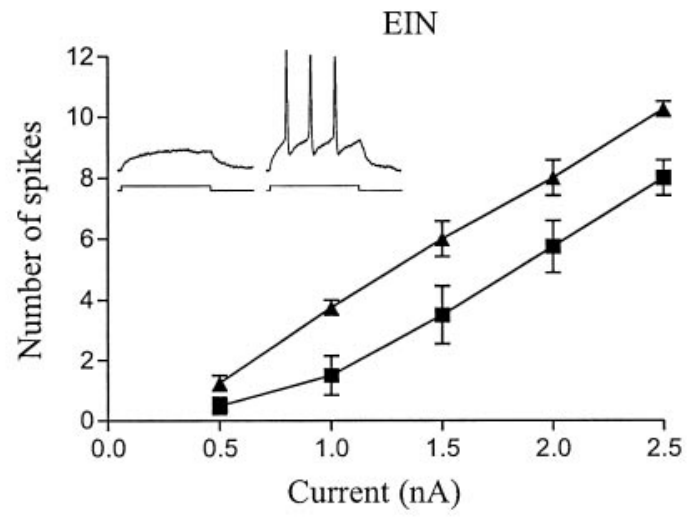

B

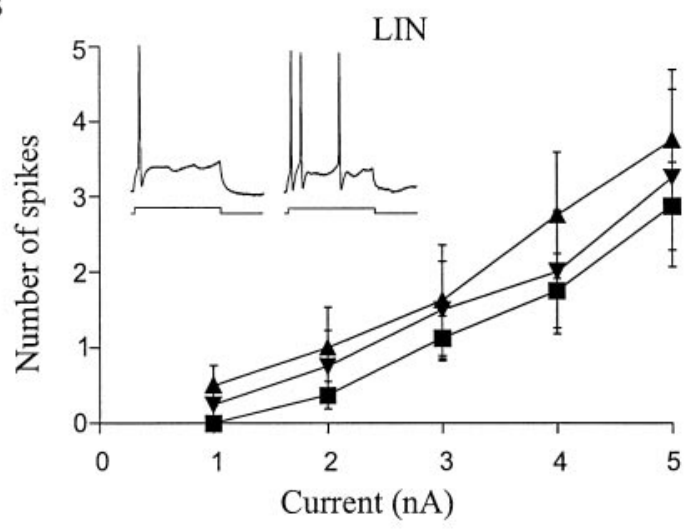

D

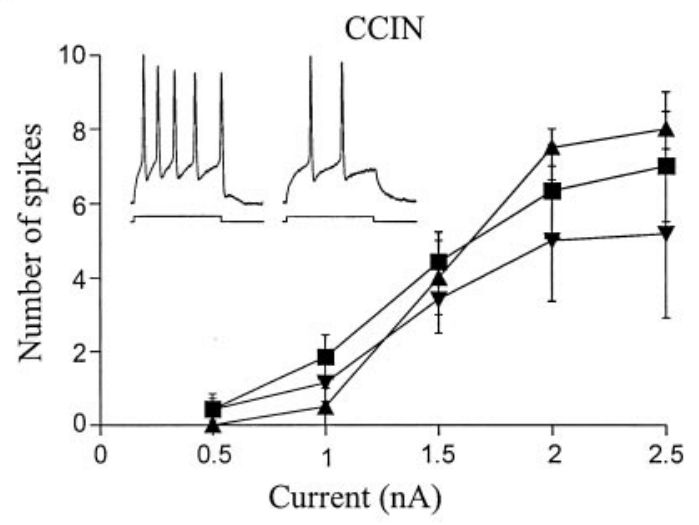

$\mathbf{E}$

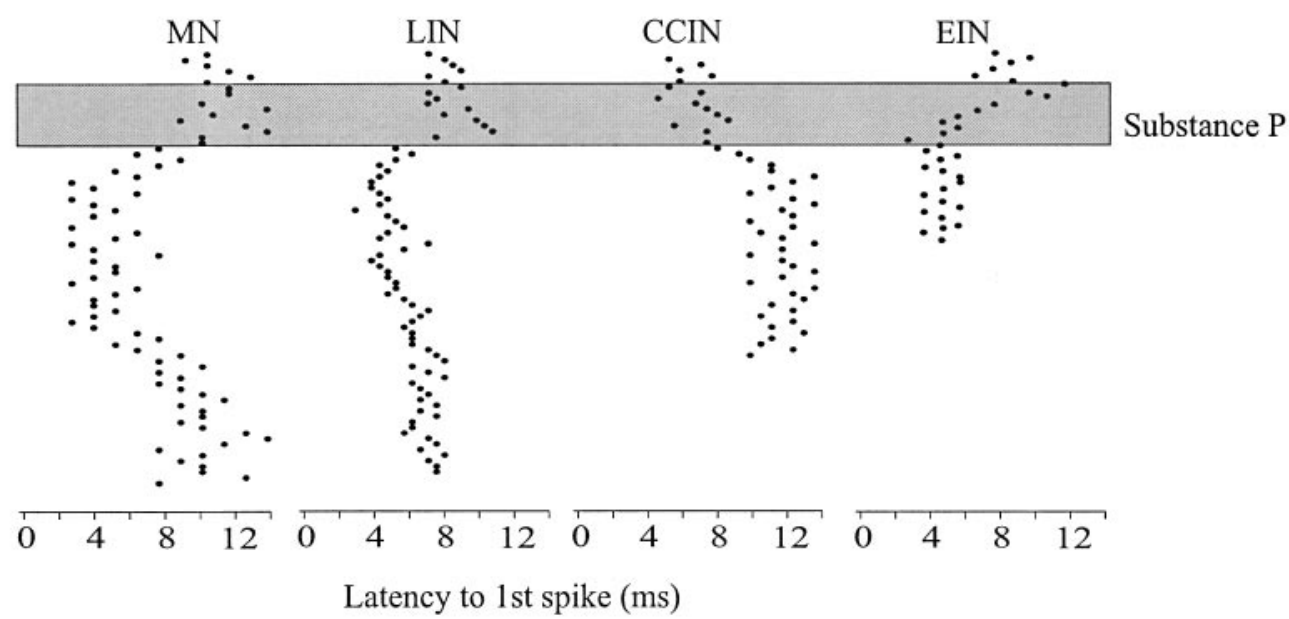

Figure 10. Substance P modulates the spiking in response to depolarizing current pulses in spinal neurons. Spiking was elicited by injecting 100 msec depolarizing current pulses into the somata under current clamp. The membrane potential in control and in the presence of substance $\mathrm{P}$ was set at -70 $\mathrm{mV}$ by current injection using single electrode current clamp. Substance $\mathrm{P}$ increased the spiking in motor neurons $(A)$, LINs $(B)$, and EINs $(C)$ but usually reduced the spiking in CCINs $(D)$. E. In addition to the effect on the number of spikes, substance P reduced the latency to the first spike in motor neurons and LINs, but increased it in CCINs. Each point for the different types of neurons is the latency to the first spike after the onset of the depolarizing current pulse in control, during substance $\mathrm{P}$ application, and after wash-off. The experiments shown here were performed in the presence of CNQX $(10 \mu \mathrm{M})$, AP5 $(100 \mu \mathrm{M})$, and strychnine $(5 \mu \mathrm{M})$ to block synaptic inputs. Data from 14 motor neurons, 5 LINs, 8 CCINs, and 8 EINs are shown in $A-D$ and from single representative cells of each type in $E$.

examining miniature PSPs in the presence of TTX (data not shown). The substance P-mediated depolarization of EINs in the presence of TTX was larger than in motor neurons, suggesting that substance $\mathrm{P}$ has a greater direct effect on the membrane potential of these interneurons.
The cellular effects of substance $\mathrm{P}$ depended on the type of neuron studied. For example, spiking in response to depolarizing current pulses was increased in motor neurons, LINs, and EINs, but usually reduced in CCINs. This appears to be caused by at least two factors. A reduction of the $\mathrm{AHP}_{\mathrm{Ca}}$, which is involved in 
A

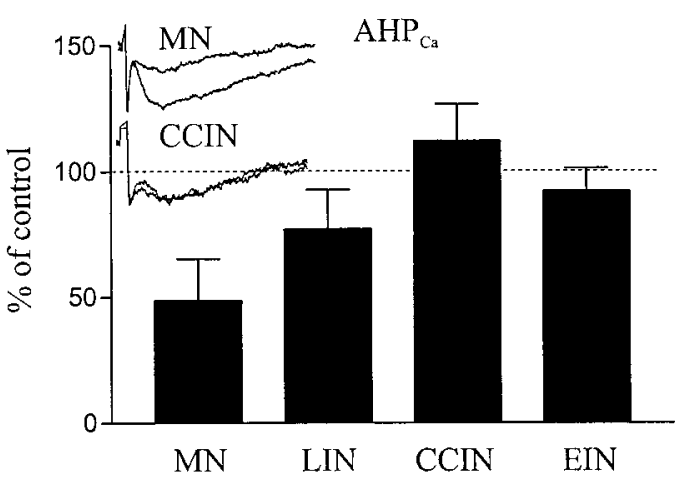

C

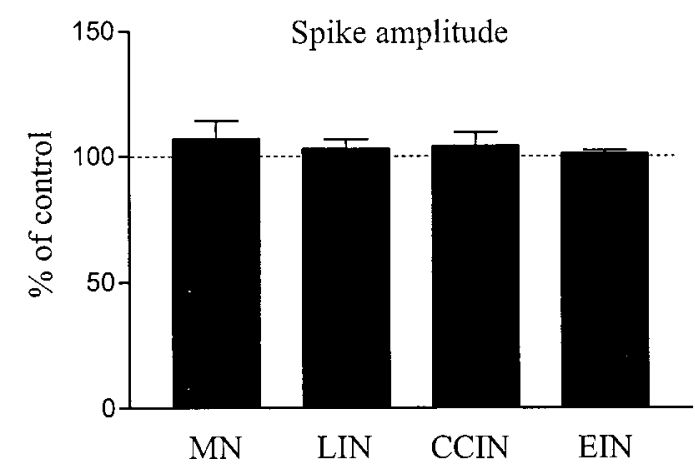

B

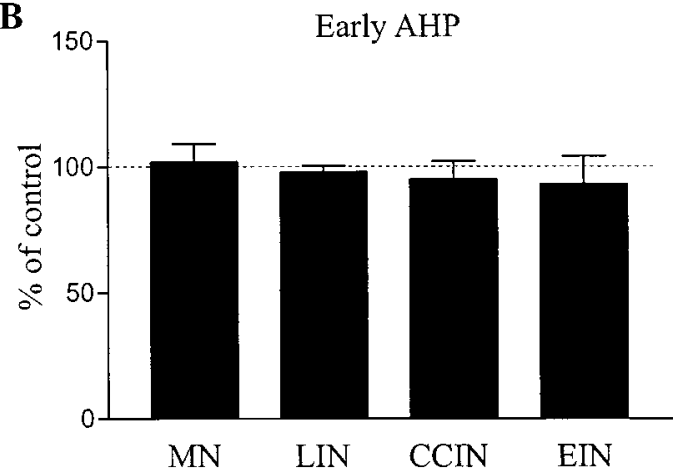

D

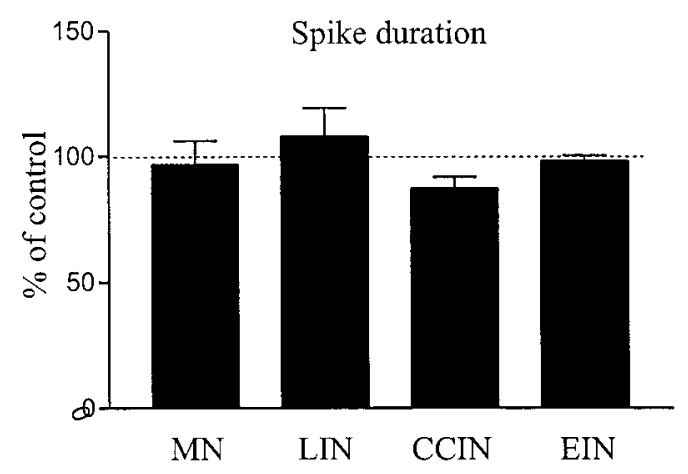

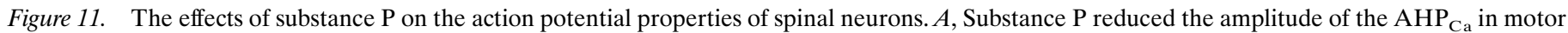

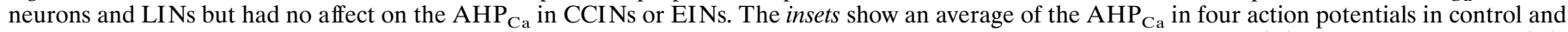

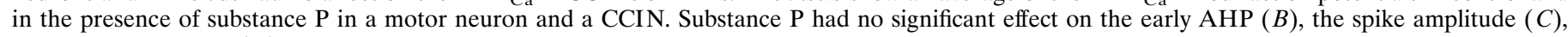
or the spike duration $(D)$ in any type of neuron. Data from 14 motor neurons, 5 LINs, 8 CCINs, and 8 EINs are shown.

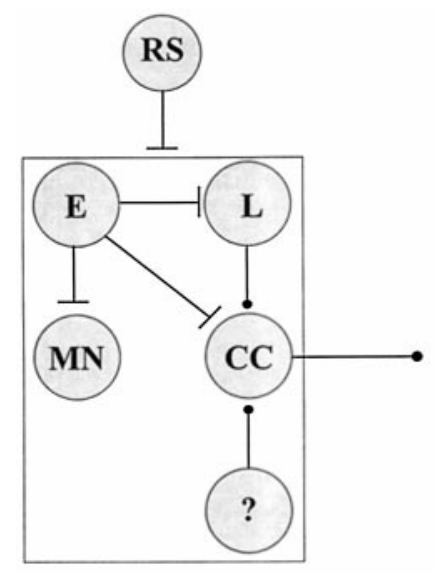

Control

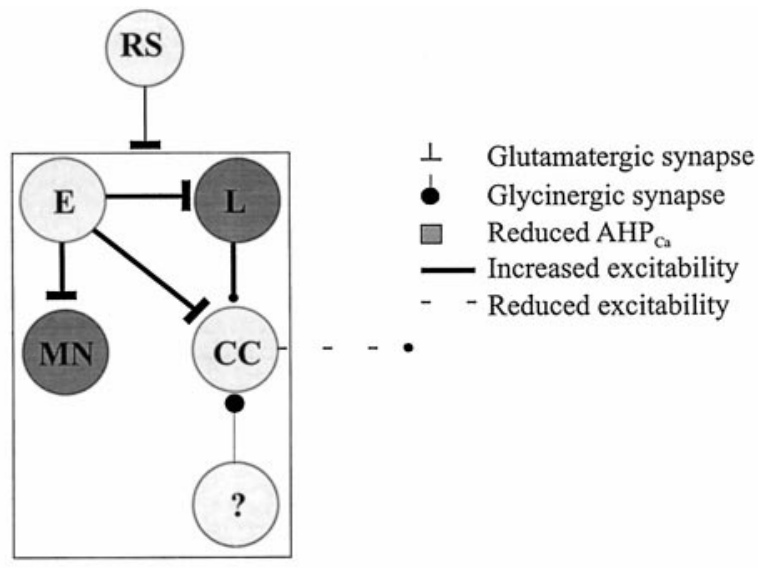

Substance P

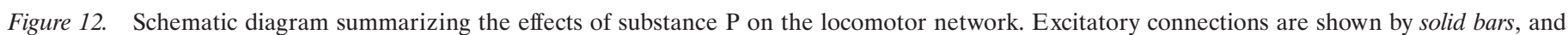

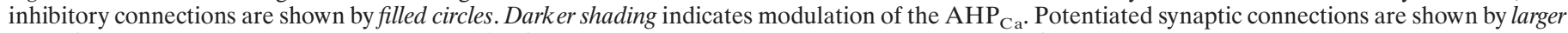

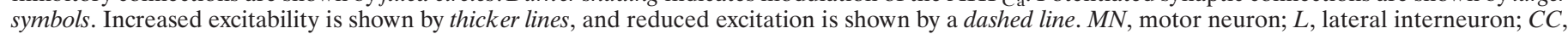
CCIN; $R S$, reticulospinal input; $E$, EIN.

spike frequency regulation (Gustafsson 1974; Wallén et al., 1989), could account for the increased number of spikes in motor neurons and LINs. Because the $\mathrm{AHP}_{\mathrm{Ca}}$ was not affected in CCINs or EINs, the modulation of spiking in these cells must be caused by the modulation of other potassium (Storm 1988; Atkins et al., 1990) or voltage-activated calcium conductances (Matsushima et al., 1993). In addition, because the spike latency is also modulated in each cell type, there must also be an effect on conductances that regulate the onset of spiking (Storm, 1988).
The $\mathrm{AHP}_{\mathrm{Ca}}$ is suggested to be involved in regulating spike frequency during a burst, particularly at low burst frequencies (El Manira et al., 1994; Tegnér et al., 1998). Correlated effects on the burst frequency and the $\mathrm{AHP}_{\mathrm{Ca}}$ amplitude have been shown for dopamine (McPherson and Kemnitz, 1994; Schotland et al., 1995), 5-HT (Harris-Warrick and Cohen, 1985; Wallén et al., 1989), and GABA (Alford et al., 1991; Matsushima et al., 1993; Tegnér et al., 1993); in each case, a reduction of the $\mathrm{AHP}_{\mathrm{Ca}}$ is associated with a reduced burst rate. At the network level, sub- 
stance $\mathrm{P}$ increases the burst rate, the largest effect occurring at low initial burst frequencies (Parker et al., 1998). Because the $\mathrm{AHP}_{\mathrm{Ca}}$ was not usually affected in EINs or CCINs, modulation of the $\mathrm{AHP}_{\mathrm{Ca}}$ does not appear to be important in the substance $\mathrm{P}$-mediated increase in burst frequency. The effect of substance $\mathrm{P}$ on the $\mathrm{AHP}_{\mathrm{Ca}}$ in motor neurons and LINs will, however, result in an increase in the number of spikes in these cells in response to the same excitatory drive, which, in the case of motor neurons, potentiate the motor response.

\section{Contribution of the cellular and synaptic modulation to the network modulation}

Several cellular and synaptic mechanisms could contribute to the substance P-mediated increase in burst frequency. For example, a general increase in network excitation, both experimentally (Grillner et al., 1981; Brodin et al., 1985) and in simulations (Grillner et al., 1988; Hellgren et al., 1992), increases the burst frequency. Substance P increases glutamate release, potentiates postsynaptic NMDA responses, and increases the excitability of EINs, all of which will increase excitatory drive to the network. Changes in the strength of reciprocal inhibition can also modulate the burst frequency (Grillner and Wallén, 1980; Hellgren et al., 1992; McDearmid et al., 1997). Although substance P did not directly affect CCIN-mediated reciprocal synaptic inputs, at least not in motor neurons or unidentified gray matter neurons, the reduction in CCIN spiking in response to depolarization is functionally equivalent, because the reduced number of spikes during each CCIN burst will reduce the summed reciprocal synaptic input.

The increased spiking of the LINs could also modulate reciprocal inhibition. Monosynaptic LIN inputs to CCINs (Buchanan, 1982) were suggested to contribute to burst frequency regulation (Grillner et al., 1988; Wallén et al., 1992), particularly at higher burst rates. However, the role of the LINs has been questioned because the activity of LINs is not modulated as the NMDAinduced burst rate increases (Fagerstedt et al., 1995). However, incorporating LINs to a simulated network increases the burst frequency (Hellgren et al., 1992), suggesting that the recruitment of LINs, as would occur through an increase in their excitability, can increase the burst rate. Increased LIN spiking, combined with the reduced spiking of CCINs, could thus contribute to the reduction of CCIN-mediated reciprocal inhibition (Fig. 12).

The effects of substance $\mathrm{P}$ shown in this paper could thus contribute to an increase in the burst frequency. However, the cellular and synaptic modulation shown here lasts for, at most, 2 hr, whereas the network effects of $1 \mu \mathrm{M}$ substance $\mathrm{P}$, the concentration used in this paper, last in excess of $24 \mathrm{hr}$ (Parker et al., 1998). The effects reported in this paper, thus, cannot account for the maintenance of the long-term modulation but may be important in the induction stage and/or in the short-term effects of nanomolar concentrations of substance $P$.

There are other candidate cellular and synaptic effects that could contribute to the long-term network modulation. A more detailed analysis of the modulation of synaptic transmission between identified premotor interneurons could provide insight into mechanisms underlying the long-term network modulation, as could the effects of substance P on low voltage-activated calcium conductances (Tegnér et al., 1997), NMDA-induced oscillations (J. Tegnér and S. Grillner, unpublished observation), or other membrane conductances (Calabrese and De Schutter, 1992). Two further types of network neuron, the contralateral and ipsilateral inhibitory segmental interneurons (Buchanan and Grillner, 1988;
Ohta et al., 1991; Wallén et al., 1993), remain to be examined. These neurons may have a role in network activity at the segmental level and, thus, be important targets for substance P. Finally, although the long-term modulation of the burst frequency does not require the presence of NMDA or network activity for its induction (Parker et al., 1998), the effects of substance P on cellular and synaptic properties of the neurons may be statedependent and, thus, differ quantitatively and qualitatively when elicited during NMDA-induced fictive locomotion.

In addition to the modulation of the burst frequency, substance $\mathrm{P}$ also makes the activity more regular (Parker et al., 1998). Computer simulations suggest that the strength of synaptic connections between EINs and CCINs (Hellgren et al., 1992) and the properties of low voltage-activated calcium conductances (Tegnér et al., 1997) can modulate the burst regularity, particularly at low frequencies. Further analysis may reveal insights into the mechanisms that underlie this important aspect of network operation. This paper is thus a first step in the analysis of the cellular and synaptic mechanisms that contribute to the long-term modulation of the locomotor network.

\section{REFERENCES}

Alford S, Christenson J, Grillner S (1991) Presynaptic GABA And $\mathrm{GABA}_{\mathrm{B}}$ receptor-mediated phasic modulation in axons of spinal motor interneurons. Eur J Neurosci 3:107-117.

Asher P, Nowak L (1988) The role of divalent cations in the $N$-methylD-aspartate responses of mouse central neurons in culture. J Physiol (Lond) 339:247-266.

Atkins PT, Surmeier DJ, Kitai ST (1990) Muscarinic modulation of a transient $\mathrm{K}^{+}$conductance in rat neostriatal neurones. Nature 344:240-242.

Bekkers JM, Stevens CF (1989) NMDA and non-NMDA receptors are co-localized at individual excitatory synapses in cultured rat hippocampus. Nature 341:230-233.

Brodin L, Grillner S, Rovainen CM (1985) NMDA, kainate and quisqualate receptors and the generation of fictive locomotion in the lamprey spinal cord. Brain Res 325:302-306.

Brodin L, Dale N, Christenson J, Storm-Mathisen J, Hökfelt T, Grillner S (1990) Three types of GABA-immunoreactive cells in the lamprey spinal cord. Brain Res 508:172-175.

Buchanan JT (1982) Identification of interneurons with contralateral, caudal axons in the lamprey spinal cord: synaptic interactions and morphology. J Neurophysiol 47:961-975.

Buchanan JT (1993) Electrophysiological properties of identified classes of lamprey spinal neurons. J Neurophysiol 70:2313-2325.

Buchanan JT, Grillner S (1987) Newly identified glutamate interneurons and their role in locomotion in the lamprey spinal cord. Science 236:312-314.

Buchanan JT, Grillner S (1988) A new class of small inhibitory interneurones in the lamprey spinal cord. Brain Res 438:404-407.

Buchanan JT, Grillner S, Cullheim S, Risling M (1989) Identification of excitatory interneurons contributing to generation of locomotion in lamprey: structure, pharmacology, and function. J Neurophysiol 62:59-69.

Byrne JH, Kandel ER (1996) Presynaptic facilitation revisited: state and time-dependence. J Neurosci 16:425-435.

Calabrese RL, De Schutter E (1992) Motor-pattern-generating networks in invertebrates: modelling our way toward understanding. Trends Neurosci 15:439-445.

Capogna M, Gähwiler BH, Thompson SM (1995) Presynaptic enhancement of inhibitory synaptic transmission by protein kinases $\mathrm{A}$ and $\mathrm{C}$ in the rat hippocampus in vitro. J Neurosci 15:1249-1250.

Christenson J, Lagerback PA, Grillner S (1988) The dorsal cell, one class of primary sensory neuron in the lamprey spinal cord. II. A lightand electron microscopical study. Brain Res 440:9-17.

Dale N, Grillner S (1986) Dual component synaptic potentials in the lamprey mediated by excitatory amino acids. J Neurosci 6:2653-2661.

El Manira A, Tegnér J, Grillner S (1994) Calcium-dependent potassium channels play a critical role for burst termination in the locomotor network in lamprey. J Neurophysiol 72:1852-1861. 
Fagerstedt P, Wallén P, Grillner S (1995) Activity of interneurons during fictive swimming in the lamprey. IBRO Abstr 1:346.

Grillner S, Wallén P (1980) Does the central pattern generator for locomotion in the lamprey depend on glycine inhibition. Acta Physiol Scand 110:103-105.

Grillner S, McClellan A, Sigvardt K, Wallén P, Wilén M (1981) Activation of NMDA receptors elicits "fictive locomotion" in lamprey spinal cord in vitro. Acta Physiol Scand 113:549-551.

Grillner S, Buchanan J, Lansner A (1988) Simulations of the segmental burst generating network for locomotion in lamprey. Neurosci Lett 89:31-35.

Grillner S, Deliagina T, Ekeberg Ö, El Manira A, Hill RH, Lansner A, Orlovsky O, Wallén P (1995) Neural networks that co-ordinate locomotion and body orientation in lamprey. Trends Neurosci 18:270-279.

Gustafsson B (1974) Afterhyperpolarisation and control of repetitive firing in spinal neurons of the cat. Acta Physiol Scand 416:1-47.

Harris-Warrick RM, Cohen AH (1985) Serotonin modulates the central pattern generator for locomotion in the isolated lamprey spinal cord. $\mathbf{J}$ Exp Biol 116:27-46.

Harris-Warrick RM, Marder E, Selverston AI, Moulins M (1992) Dynamic Biological Networks. Cambridge, MA: MIT.

Hellgren J, Grillner S, Lansner A (1992) Computer simulation of the segmental neural network generating locomotion in lamprey by using populations of network interneurons. Biol Cybern 68:1-13.

Katz B (1966) Nerve, muscle and synapse. New York: McGraw Hill.

Matsushima T, Tegnér J, Hill R, Grillner (1993) GABA $_{\mathrm{B}}$-receptor activation causes a depression of low and high voltage-activated $\mathrm{Ca}^{2+}$ currents, postinhibitory rebound and postspike afterhyperpolarisation in lamprey neurons. J Neurophysiol 70:2606-2619.

McDearmid JR, Scrymgeour-Wedderburn J, Sillar KT (1997) Aminergic modulation of glycine release in a spinal network controlling swimming in Xenopus laevis. J Physiol (Lond) 503:111-117.

McPherson DR, Kemnitz CP (1994) Modulation of fictive swimming and motoneuron physiology by dopamine, and its immunocytochemical localization in the spinal cord. Neurosci Lett 166:23-26.

Ohta Y, Dubuc R, Grillner S (1991) A new population of neurons with crossed axons in the lamprey spinal cord. Brain Res 564:143-148.

Parfitt KD, Madison DV (1993) Phorbol esters enhance synaptic transmission by a presynaptic, calcium-dependent mechanism in rat hippocampus. J Physiol (Lond) 471:245-268.

Parker D, Grillner S (1996) Tachykinin-mediated modulation of sensory neurons, interneurons, and synaptic transmission in the lamprey spinal cord. J Neurophysiol 76:4031-4039.

Parker D, Svensson E, Grillner S (1997) Substance P modulates mechanosensory afferents in the lamprey via a protein kinase C-mediated reduction of potassium conductances. Eur J Neurosci 9:2064-2076.

Parker D, Zhang W, Grillner S (1998) Substance P modulates NMDA responses and causes long-term protein synthesis-dependent modulation of the lamprey locomotor network. J Neurosci 18:4800-4813.

Roberts A (1990) How does a nervous system produce behaviour? A case study in neurobiology. Sci Prog 74:31-51.

Rovainen CM (1974) Synaptic interactions of identified nerve cells in the spinal cord of the sea lamprey. J Comp Neurol 154:189-206.

Safronov BV, Baev KV, Batueva IV, Rusin KI (1989) Peculiarities of receptor-channel complexes for inhibitory mediators in the membranes of lamprey spinal cord neurones. Neurosci Lett 102:82-86.

Schotland J, Shupliakov O, Wikström M, Brodin L, Srinivasan M, You Z, Herrera-Marschitz M, Zhang W, Hökfelt T, Grillner S (1995) Control of lamprey locomotor neurons by colocalized monoamine transmitters. Nature 374:266-268.

Sillar KT, Roberts A (1991) Segregation of NMDA and non-NMDA receptors at separate synaptic contacts: evidence from spontaneous EPSPs in Xenopus embryo spinal neurons. Brain Res 545:24-32.

Storm JF (1988) Temporal inactivation by a slowly inactivating $\mathrm{K}^{+}$current in hippocampal neurons. Nature 336:379-381.

Tegnér J, Lansner A, Grillner S (1998) Modulation of burst frequency by calcium-dependent potassium channels in the lamprey locomotor system-dependence of the activity level. J Comp Neurosci 5:121-140.

Tegnér J, Matsushima T, El Manira A, Grillner S (1993) The spinal GABA system modulates burst frequency and intersegmental coordination in the lamprey: differential effects of GABAA and $\mathrm{GABA}_{\mathrm{B}}$ receptors. J Neurophysiol 69:647-657.

Tegnér J, Hellgren-Kotaleski J, Lansner A, Grillner S (1997) Lowvoltage-activated calcium channels in the lamprey locomotor network: simulation and experiment. J Neurophysiol 77:1795-1812.

Tråven HGC, Brodin L, Lansner A, Ekeberg Ö, Wallén P, Grillner S (1993) Computer simulations of NMDA and non-NMDA mediated synaptic drive: sensory and supraspinal modulation of neurons and small networks. J Neurophysiol 70:695-709.

Van Dongen P, Hökfelt T, Grillner S, Verhofsted AAJ, Steinbush HWM, Cuello AC, Terenius L (1985) Imuunohistochemical demonstration of some putative neurotransmitters in the lamprey spinal cord and spinal ganglia: 5-hydroxytryptamine, tachykinin, and neuropeptide $\mathrm{Y}$ immunoreactive neurons and fibers. J Comp Neurol 234:501-522.

Van Dongen P, Theodorsson-Norheim E, Brodin E, Hökfelt T, Grillner S, Peters A, Cuello AC, Forssman WG, Reinecke M, Singer EA, Lazarus LH (1986) Immunohistochemical and chromatographic studies of peptides with tachykinin-like immunoreactivity in the central nervous system of the lamprey. Peptides 7:297-313.

Wallén P, Buchanan JT, Grillner S, Hill RH, Christenson J, Hökfelt T (1989) Effects of 5-hydroxytryptamine on the afterhyperpolarisation, spike frequency regulation and oscillatory membrane properties in lamprey spinal cord nerves. J Neurophysiol 61:759-768.

Wallén P, Ekeberg Ö, Lansner A, Brodin L, Traven H, Grillner S (1992) A computer based model for realistic simulations of neural networks II: the segmental network generating locomotor rhythmicity in the lamprey. J Neurophysiol 68:1939-1950.

Wallén P, Shupliakov O, Hill RH (1993) Origin of phasic synaptic inhibition in myotomal motoneurons during fictive locomotion in the lamprey. Exp Brain Res 96:194-202.

Waugh D, Bondareva V, Rusakov Y, Bjenning C, Nielson PF, Conlon JM (1995) Tachykinins with unusual structural features from a urodele, the amphiuma, an elasmobranch, the hammerhead shark, and an agnathan, the river lamprey. Peptides 16:615-621.

Zhang W, Pombal M, El Manira A, Grillner S (1996) Rostrocaudal distribution of 5-HT innervation in the lamprey spinal cord and differential effects of 5-HT on fictive locomotion. J Comp Neurol 374:278-290. 